\title{
Análisis de la implementación de Rincones Lectores en Jardines Infantiles
}

\section{Analysis of the implementation of Reader Corners in Children's Gardens}

\section{Camila Fernanda Guerra Muñoz (i)}

Universidad de Valparaíso, Facultad de Medicina, Escuela de Educación Parvularia, Valparaíso, Chile.

\section{Francisca JAVIERA GUtIÉRREZ LINEROS (D)}

Universidad de Valparaíso, Facultad de Medicina, Escuela de Educación Parvularia, Valparaíso, Chile.

\section{Nicole Esther Núñez Martínez (D)}

Universidad de Valparaíso, Facultad de Medicina, Escuela de Educación Parvularia, Valparaíso, Chile.

\section{Scarlett Constanza Sánchez Mardones (D)}

Universidad de Valparaíso, Facultad de Medicina, Escuela de Educación Parvularia, Valparaíso, Chile.

\section{Autor de Correspondencia: Nicole Esther Núñez Martínez}

Universidad de Valparaíso, Facultad de Medicina, Escuela de Educación Parvularia, Valparaíso, Chile. mail: nenm1996@gmail.com

\section{RESUMEN}

Un Rincón lector es una innovación pedagógica que se define como un espacio caracterizado por ser cómodo, acogedor y accesible donde los/as niños/as se sientan identificados, generando una variedad de experiencias y vivencias lectoras con diferentes cuentos que motiva al lector a darse la oportunidad de compartir con otros y transmitir la importancia que tiene la lectura desde un enfoque centralizado en el disfrute, lo lúdico y en el diálogo. El objetivo de este estudio fue analizar las transformaciones que se producen en la comunidad educativa al implementar una innovación pedagógica llamada rincones lectores en jardines infantiles de la comuna de San Antonio, región de Valparaíso, Chile. Se diseñó un estudio cualitativo, mediante el uso de entrevistas semiestructuradas realizadas a equipos educativos de tres jardines infantiles de la comuna. Los resultados se analizaron de manera sistemática en base a tres categorías principales: I. Motivación de los participantes en la implementación de rincones lectores; II. Proceso de implementación de rincones lectores y III. Percepción del efecto de los rincones lectores en las comunidades educativas. De cada una de estas categorías principales se derivaron subcategorías 
(subnodos) que fueron analizadas individualmente. A partir de los análisis de las entrevistas realizadas, surgieron hallazgos en relación al efecto positivo que generó la implementación de los rincones lectores, los cuales enfatizan en el desarrollo emocional y cognitivo de los/as niños/as, el vínculo entre la comunidad educativa y el trabajo en equipo entre los actores involucrados, entre otros.

Palabras clave: Lectura, lectura en voz alta, fomento lector, rincón lector y mediador.

\section{ABSTRACT}

A Reading Corner is a pedagogical innovation that is defined as a space characterized by being comfortable, welcoming and accessible where children feel identified, generating a variety of experiences and reading experiences with different stories that motivates the reader to give themselves the opportunity to share with others and convey the importance that reading has from a centralized approach to enjoyment, playful and dialogue. The objective of this study was to analyze the transformations that occur in the educational community by implementing this pedagogical innovation in children's gardens in the San Antonio district, Valparaíso region, Chile. A qualitative study was designed, using semi-structured interviews conducted on teams from three children's gardens in the district. The results were systematically analyzed based on three main categories: I. Motivation of participants in the implementation of reader corners; II. Process of implementation of reader corners and III. Perception of the effect of reader corners on educational communities. Subcategories were derived from each of these main categories and were analyzed individually. From the analysis of the interviews conducted, findings emerged regarding the positive effect generated by the implementation of the reader corners, which emphasize the emotional and cognitive development of children, the link between the educational community and teamwork among the actors involved, among others.

Keywords: Reading, reading aloud, reading promotion, reading corner and mediator.

\section{Introducción}

Una de las problemáticas que hoy en día enfrenta Chile, en términos de desarrollo del lenguaje, es que la mayoría de los chilenos no tienen hábitos lectores. El 44\% de los adultos chilenos se auto percibe como poco lector o no lector. Por otra parte, de acuerdo al estudio de comportamiento lector " $E l$ 84\% de los chilenos no demuestra una comprensión adecuada de textos largos y complejos si el contenido no les resulta familiar. Los lectores entre $15 y$ 34 años tienen un nivel de comprensión lectora mejor que los de 35 a 65 años" "Estudio de Comportamiento Lector: 84\% de Los Chilenos No Comprende Adecuadamente Lo Que Lee | Ministerio de Las Culturas, Las Artes y El Patrimonio" n.d.).

Para Medina (2006), la sociedad en que vivimos exige contar con un mayor índice de habilidades lectoras, donde no solo deben ser capaces de decodificar el significado de las palabras, más bien, se espera que manejen cualquier tipo de información, tales como: leer comprensivamente textos, comunicarse de manera clara y eficaz, resolver problemas, desarrollar un pensamiento crítico, interpretar y evaluar los mensajes de los medios de comunicación y responder a un entorno en constante cambio, entre otros.

A raíz de lo anterior, se puede señalar que la sociedad no se percata de cómo se están llevando los procesos de iniciación a la lectura en la educación inicial, perdiendo el valor inicial que ésta posee. Así lo respalda Araos (2016), quien señala que la lectura hoy está en crisis, puesto que, si bien se reconoce la importancia de la lectura en la infancia, cada vez más pierde su valor, ya que, se están centrando en que los/as niños/as deben aprender a leer, en vez, de fomentar la lectura de una manera que acerque y permita a ellos/as, querer disfrutar, experimentar y vivir buenas experiencias con los libros, generando así, el interés y motivación en esta etapa y en las que vienen.

En este punto, es necesario tener en cuenta, que los/as niños/as, desde que nacen comienzan a relacionarse con un mundo totalmente alfabetizado, lo que conlleva a estar expuestos a vivir 
experiencias lectoras mucho antes de ingresar a un establecimiento educacional. Así lo respalda Ferreiro, quien es citada por Romero (2004), para dicha autora, antes que los/as niños/as ingresan a primer grado, ya traen información sobre el sistema de la lengua escrita, sobre todo en las zonas urbanas, donde hay una mayor accesibilidad a diversas manifestaciones del lenguaje escrito. Como, por ejemplo, el simple hecho de caminar por la calle y observar los letreros publicitarios o ver como se escribe su nombre. Esto permite acercar poco a poco a los/as niños/as al reconocimiento visual de las letras. "Se aprende a leer - a interpretar, a construir sentido, a pensar en el lenguaje escrito y a disfrutarlo- a través de la experiencia literaria, mucho antes de aprender a decodificar, leer y escribir en un sentido alfabético." (Belmar, Bombal, Henríquez, Pérez y Ruiz-Tagle, 2018, p.23), no obstante, esta experiencia es sólo una de muchas en las cuales los/as niños/as se pueden vincular con la palabra.

En relación a lo anterior, se debería enfatizar en realizar preguntas mediadoras asociadas a las experiencias personales de cada niño/a, para que la lectura sea más significativa. Por ejemplo: ¿Cómo se sintieron ustedes con lo ocurrido en la historia? ¿Les es familiar esta historia? ¿A qué los lleva a pensar? ¿Cuándo observaron la portada cómo se imaginaron que iba a ser?.

Chambers (2015), señala que los maestros deben generar preguntas que permitan a los lectores poder descubrir y compartir su comprensión de los pedazos que para ellos/as están claros. En este punto, el docente sintetiza lo que el grupo pretende decir, de modo que se pueda considerar e incluso cambiar el foco de la conversación si lo desean. Por otro lado, se deben potenciar sus respuestas, de manera que no tengan miedo a participar porque creen que está mal, sino que de- mostrarles que serán escuchados y respetados, no sólo por parte del docente, también por todo el grupo presente. Es decir, si la experiencia invita a la conversación frente a una lectura, las preguntas que surgirán, tanto de parte de los/as niños/ as, como del adulto se darán de manera natural. Es por ello, que se debe tener en consideración, que no hay una única pregunta y respuesta de los cuentos, sino más bien, se pueden deducir distintas ideas según la vivencia de cada niño/a.

El énfasis que se otorga al desarrollo de estas competencias o herramientas lectoras, por parte de los docentes, como se menciona anteriormente, deja ver que en la práctica el acento está en la técnica de codificación y decodificación y no en la complejidad de competencias que a través de ellas se pueden movilizar en estas primeras edades. Es decir, éstas se centran en que los individuos lean, pero no necesariamente enfocándose en brindar espacios agradables, experiencias placenteras y por sobre todo en que comprendan lo que están leyendo. Provocando que los/as niños/as crezcan con la idea de que leer es sólo para lograr una buena calificación, y, por lo tanto, no genere motivación, disfrute ni interés por la lectura.

"Nadie, en definitiva, podrá realizar en nuestro lugar el fatigoso recorrido que nos permitirá aprender. Sin grandes motivaciones interiores, el más prestigioso título adquirido con dinero no nos aportará ningún conocimiento verdadero ni propiciará ninguna auténtica metamorfosis del espiritu." (Ordine, 2013, p. 9).

En la realidad educativa, son los docentes los encargados de aproximar a los/as niños/as la lectura de una forma distinta donde se transmita el placer de leer y la capacidad de valorar los libros por lo que contienen y por el significado que cada uno le otorgue. Siguiendo con lo anterior, ellos/ as dejan de lado la potenciación de otras áreas relevantes para el desarrollo cognitivo de los/as 
niños/as, tales como la expresión oral, creatividad, comprensión, entre otras. Ruay (2010), hace referencia a este punto, y alude a que pareciera que el rol de este equipo enfatiza cada vez más en esta rutina evaluativa, perdiendo su carácter especializado, es decir, el preocuparse por el desarrollo integral de los/as niños/as, desde una mirada empática, respetuosa y creyendo en sus potencialidades. Por ende, deben dejar de centrar su trabajo en lo técnico, sin olvidar que deben tener presente el rol fundamental que cumplen en el contexto pedagógico. Es por ello, que en éste se deben generar estrategias que les sean atractivas, que no solo dispongan de una biblioteca con libros o cuentos, sino más bien, contar con un espacio destinado a la lectura, comodidad, reflexión, creatividad, emoción e imaginación.

Si bien, existen diferentes estrategias para potenciar el fomento lector, no se observa una dedicación para implementar estos espacios de tal forma que resulte sutil, delicado, estético y agradable al momento de dar a conocer un cuento o un libro literario, ya que, no se contempla el mostrarlo como algo nuevo, innovador y didáctico, de manera que sea entretenido para los/as niños/as. Si se lograra vincular a los párvulos desde esta perspectiva con los libros, se permitirá instalar un nexo más cercano y cuidadoso, ya que, como lo señala Ramos "El propósito es lograr que niñas y niños se transformen en asiduos lectores, por convicción y no por imposición.” (2009, p.19). Es decir, que sea un interés natural y espontáneo por tomar los libros y saber lo que ocurre en las historias ahí contenidas.

Una estrategia atractiva para fomentar la lectura en primera infancia, es implementar rincones lectores, los cuales deben reunir las características necesarias para invitar a los/as niños/as a explorar, leer y escuchar narraciones, que brinden el disfrute. Ramírez (2015), plantea que los espacios que concentran libros de diversas índoles constituyen un lugar privilegiado para incentivar el placer de la lectura y utilizar éste como un complemento fundamental en la formación de niños/as y jóvenes. El rincón lector, debe estar acondicionado para ser grato e invitar a la lectura, además, debe cumplir con otorgar un espacio que facilite información, lectura y aprendizaje, siendo una instancia que genere experiencias lúdicas y significativas, como un lugar que brinde oportunidades de descubrimiento.

Por lo tanto, no basta solo contar con una biblioteca de aula llena de cuentos, si no se le da la importancia ni el valor a cada uno de éstos. En este punto, el equipo educativo tiene una labor sumamente relevante, ya que, como es mencionado anteriormente, son ellos/as los encargados de generar, condicionar e intencionar espacios íntimos, cálidos y cómodos que inviten, motiven y llamen la atención de los/as niños/as, provocando un acercamiento placentero y un momento donde se les permita poder desarrollar sus emociones, imaginación, capacidades de percepción y comprensión, entre muchos más beneficios que se dan gracias a las experiencias lectoras y más aún si se da en un espacio agradable, propiciando el cuidado que éste requiere, cautelando el uso adecuado de los libros y de todos los materiales dispuestos, lo que en general no ocurre, pues se suelen observar espacios con libros en deterioro y muchas veces tirados en el suelo o rayados, rotos o sin las páginas completas.

Es por esto, que el Ministerio de Educación (MINEDUC) destaca, que los/as niños/as que han tenido un acercamiento a la lectura desde los primeros años de vida tienen mayores posibilidades de leer un cuento cuando quieran y deban hacerlo. "La lectura es un proceso "maduracional", de 
pronto entienden cómo las letras se empiezan a juntar y ese proceso muchas veces ocurre sin necesidad de haber pasado por un proceso formal de lectoescritura." (2018, p.16). Es decir, que este proceso si se vive de manera significativa y con experiencias asociadas a encuentros con la lectura y escritura, se logrará en los/as niños/as un acercamiento natural.

Actualmente, el Plan Nacional de la Lectura 2015 - 2020, contempla la creación de bibliotecas de aula, las cuales han sido implementadas en niveles de transición I y II de todos los establecimientos educacionales subvencionados del país, además, de salas cunas y jardines infantiles pertenecientes a la Junta Nacional de Jardines Infantiles (JUNJI) y de Fundación Integra (INTEGRA). Sin embargo, este plan no incorpora a los jardines infantiles VTF.

Con estos antecedentes, el objetivo de este estudio fue analizar las transformaciones que se producen en la comunidad educativa al implementar una innovación pedagógica llamada rincones lectores en jardines infantiles VTF de la comuna de San Antonio.

\section{Metodología}

El estudio se desarrolló dentro de un enfoque cualitativo y el paradigma interpretativo, el instrumento que permitió recoger información fueron las entrevistas semiestructuradas, las cuales constituyeron una herramienta primordial para que el equipo de investigación reuniera, analizara y comprendiera la información, con el fin de lograr ver o conocer las percepciones del proceso de implementación del objeto de estudio.

Se ejecutaron 12 entrevistas semiestructuradas a educadoras y técnicos de Educación Parvularia, que se desempeñaban en tres jardines infantiles del programa VTF de la comuna de San Antonio en la región de Valparaíso, Chile.

Para la sistematización de la información se utilizó el software Nvivo 11, el cual es un programa de análisis cualitativo que integra las principales herramientas para trabajos textuales, multimediales, datos de encuestas y datos bibliográficos.

La información se organizó en nodos y subnodos que corresponden a las categorías y subcategorías de esta investigación. Dentro del análisis se realizó una lectura de las respuestas de diferentes actores involucrados en este proceso recogiendo diversas perspectivas, ya que, por una parte, se entrevistó al equipo gestor de esta iniciativa y por otra parte a integrantes de los equipos educativos de los tres jardines infantiles VTF.

Los hallazgos se organizaron en función de los objetivos del estudio y de las categorías apriorísticas (nodos) planteadas a partir del marco referencial de esta investigación: I. Motivación de los participantes en la implementación de rincones lectores; II. Proceso de implementación de rincones lectores y III. Percepción del efecto de los rincones lectores en las comunidades educativas. De cada una de estas categorías principales se derivaron subcategorías (subnodos) que fueron analizadas individualmente

Con los hallazgos encontrados en las entrevistas realizadas a los diferentes participantes del proyecto, se pudo establecer una frecuencia de las palabras que más presencia tuvieron en los diálogos que se sostuvieron. Para establecer esta frecuencia se utilizó el programa Nvivo 11, el cual permitió la creación de una "nube de palabras". 


\section{Resultados}

\section{Motivación de los participantes en la implementación de rincones lectores}

Esta categoría se entiende por el interés que tuvieron los diferentes actores en iniciar este proyecto en los tres jardines infantiles VTF que fueron parte del estudio, es decir, cuales fueron aquellos aspectos que los impulsaron a involucrarse en la implementación de los rincones lectores.

Desde esta primera categoría se desprenden cuatro subcategorías que presentamos a continuación:

\section{Origen de la propuesta desde el equipo gestor}

Esta subcategoría da a conocer cómo surgió la iniciativa del proyecto: "Mi primer Rincón Lector" desde la mirada del equipo gestor, el cual está compuesto por la Fundación de Desarrollo San Antonio Siglo XXI y la Ilustre Municipalidad de San Antonio, en conjunto al Programa Jardines Infantiles de la Dirección de Desarrollo Comunitario de la Ilustre Municipalidad de San Antonio.

Desde el equipo gestor, existe un diagnóstico previo en el cual las personas entrevistadas tuvieron diferentes planteamientos. Una de las motivaciones surge a partir del sello que asume la Fundación de Desarrollo San Antonio Siglo XXI, lo que responde a un compromiso con la comunidad desde lo social, cultural y educativo. Desde esta lógica E.G. 2 plantea lo siguiente:

"Dentro de los cuatro años de la fundación ... en el área educacional se empezó haciendo primero unas bi- blioaulas en dos escuelas rurales, de primero a cuarto básico, donde se compraron unos conteiner traídos de Santiago, que se adecuaban para hacer una biblioteca y este año se empezó con tres jardines infantiles el E.G. 1 junto a la Universidad de Valparaíso."

Frente a esto mismo E. G. 1 señala en relación a que estos espacios se adecuaron de la forma óptima que pudieron "una sala modular, que cumplía un doble propósito dar a los estudiantes un espacio fisico donde podían tener una sala de clases y a la vez habilitar una biblioteca."

La comuna de San Antonio tiene doce jardines infantiles VTF los cuales, no podían ser implementados en forma simultánea por los costos que esto implicaba, es por ello, que se seleccionaron como experiencia piloto solo tres de éstos, E. G. 1 plantea la cantidad de jardines infantiles donde llevar a cabo el proyecto "Se acercó gente de programas infantiles para realizar un proyecto donde realizamos 6 visitas a diferentes jardines infantiles el año 2018 y dentro de eso priorizamos tres jardines para implementar este proyecto." Respecto a esto mismo E. G. 3 se refiere al proceso de selección de los jardines infantiles participantes donde menciona que:

"En primera instancia se decidieron visitar a seis, nosotros tenemos doce jardines VTF en la comuna. $Y$ en aquella oportunidad solo visitamos seis porque sabiamos que el financiamiento no cubría para tanta cantidad de establecimientos. De esos seis jardines se priorizaron tres que necesitaban más apoyo para mejorar su gestión técnico pedagógica y ahi fue que se favoreció entonces a Pañud, Bello Horizonte y Mi Mundo de Colores, para que pudieran participar del proyecto de fomento lector con Fundación de Desarrollo San Antonio Siglo XXI."

Otra de las motivaciones, que surgió en el diagnóstico del equipo gestor fue el tema del fomento lector, no solo en educación básica, sino también 
que éste sea transferido a la primera infancia, tal como lo plantea E. G. 1:

"Dentro de nuestro diagnóstico social que levantamos en el año 2018, una de las prioridades por la comunidad fue el tema del fomento lector, entonces nosotros como fundación nos hicimos cargo y delineamos un programa que se llama "Mi Primer Rincón Lector" que buscaba renacer el goce lector en estudiantes de Educación Paroularia, en este caso de jardines VTF."

Asimismo, otra de las motivaciones surge a partir de la normativa del MINEDUC, que uno de sus objetivos es que los jardines infantiles sean acreditados y reconocidos, a partir de esto, una de las exigencias relevantes es la implementación de las bibliotecas de aula, como bien lo menciona E. G. 3:

\section{"El Ministerio de Educación tiene por normativa hoy en día que existe un estándar mínimo de calidad que tiene que ver con que los jardines puedan acreditar- se para tener reconocimiento oficial del MINEDUC y dentro de ello una de las exigencias pedagógicas es implementar en cada una de las aulas la biblioteca de aula para que efectivamente se pueda trabajar el tema de fomento lector con los/as niños/as."}

De esta manera se valoró la decisión de la Fundación de Desarrollo San Antonio Siglo XXI al tener en consideración a los jardines infantiles VTF, puesto que antes solo se trabajaba con colegios y jardines infantiles de la comunidad. Lo que fue de gran ayuda para los jardines infantiles VTF, ya que, no contaba con los recursos necesarios para poder implementar rincones lectores.

\section{Motivación personal}

Esta subcategoría hace referencia a la motivación que tuvo tanto el equipo gestor como el equipo pe- dagógico de cada jardín infantil por involucrarse en este proyecto, a partir de distintas perspectivas que tenían un objetivo en común.

En cuanto al equipo gestor, se pudo identificar primeramente una motivación personal, ya que, su contacto con la literatura responde a tener un hábito lector, señalando haber vivido una experiencia grata con la lectura permitiéndole así vincularlo a su vida cotidiana, influyendo en la decisión de formar parte de este proyecto, como bien señala E. G. 2:

"Yo no sé si sea un buen lector, pero si leo harto porque me gusta saber de distintas áreas, además, es una instancia donde puedo compartir con mi hijo, donde se produce un espacio agradable, tanto para el como para mí, donde yo le hablo lo que él me muestra tomándolo en cuenta y él se emociona y me hace gestos o los sonidos de los animales."

Asimismo, E.G. 1 agrega que el tema de la lectura es de gusto personal, es por esto y desde su punto de vista fue un detonante para impulsarlo a participar en este proyecto; también señala que durante el proceso previo de la implementación tuvo que recopilar información para apropiarse del tema y una de sus referentes fue:

"Una autora peruana que se llama Silvana Saazar Ayllón, ella decía que deben haber cuatro elementos para detonar el goce lector, primero saber leer, segundo que leer, tercero donde leer y cuarto el querer leer, éste último es el principal punto y el más dificil. En ese aspecto es fundamental el generar actividades asociadas para generar el goce en los/as niños/as, es por eso, que no tendría sentido tener libros apilados si no se va a intencionar este espacio para el desarrollo de ellos."

Esta opinión es una mirada desde lo conceptual, pues se plantea desde el conocimiento teórico que posee el entrevistado (EG2). 
Por otro lado, desde la perspectiva de los diferentes actores que son parte de los jardines infantiles, en relación a la motivación personal, aluden a que, desde este proyecto ha surgido la necesidad e interés personal de la mayor parte de las funcionarias, para perfeccionarse e ir conociendo más en profundidad el tema de la lectura en primera infancia a través de Rincones Lectores.

Uno de los participantes, del J.I.1 señala haber realizado un curso de "Cuenta cuentos", independiente de la iniciativa del proyecto, el cual fue de gran ayuda para generar diversas estrategias dentro de la implementación del Rincón Lector. Por su parte, una de las funcionarias del J.I.2 consideró que una de las motivaciones que la llevó a encantarse con este proyecto fue el sentimiento positivo que le provoca contar o narrar cuentos, debido a las expresiones que le transmiten los párvulos en esa experiencia, ya que, comenta que es enriquecedor y causa emoción el saber que los/as niños/as manifiestan interés y disfrute por lo que están oyendo y observando, al respecto ella señala:

"Yo al momento de leer un cuento me siento súper bien, es que a mi me encanta eso, que los niños me observen, me miren, que estén pendientes y que te escuchen, para uno es súper enriquecedor primero que todo, entonces yo con esas cosas me emociono, porque digo por algo estudie esto, lo que ratifica mi vocación, la que lamentablemente está mal mirada por mucha gente, desvalorada, pero cuando los niños están atentos, están felices y tu notas eso en sus caritas, dices es real, esto es lo que yo quiero y me apasiona, entonces no necesariamente es hacer el loco ni disfrazarse, ni nada, solamente buscar pequeñas cositas para que ellos estén pendiente contigo y se sienta esa cercanía entre tú y ellos."

A partir de esta implementación, otro agente del J.I.2, hace referencia a que, este proceso le per- mitió darse cuenta de la importancia que tiene la lectura desde la primera infancia y que son los adultos los que tienen la labor de acercar la lectura desde el goce. "...Ahora...yo hasta a mi hija le regalo libros, le he estado regalando libros, porque es ahi cuando te das cuenta de que, si tu empiezas desde chiquitito a regalarles libros, después les gusta y te piden, te piden libros." Desde este mismo planteamiento, otras de las personas entrevistadas en el J.I. 2 alude a la importancia de transmitirle el gusto por la lectura a los/as niños/as y en lo personal a sus hijos, ya que, considera que es algo primordial en el desarrollo de ellos/as.

"Yo tengo 3 hijos y la verdad es que me gustaría que ellos sean asiduos lectores, donde se les inculque la importancia de la lectura desde pequeñitos con esta perspectiva de goce, no solo de evaluación que es lo que normalmente vemos en la vida cotidiana."

Por último, en relación a esta sub categoría, el J.I.3 añade una perspectiva desde la mediación pedagógica, una de las entrevistadas dice que es fundamental el tono de voz, los movimientos y gestos que se tienen a la hora de leer un cuento, ya que, esto genera el interés de los/as niños/as y la motivación por seguir fomentando la lectura en la primera infancia, "A mi me encanta leerle cuentos y actuarlos, de hecho, en la inauguración de la biblioteca hicimos una obra, a mí me encanta y tengo el titiritero y lo usamos, maravilloso, me fascina.", también comenta que dentro de la jornada se realizan experiencias que propician la lectura como la selección de cuentos por parte de los/as niños/ as, lo que ha sido significativo dentro del jardín infantil, así señala:

"Para mi ha sido significativo, para los chicos igual, si tú te diste cuenta la tía les empezó a contar el cuento y ellos ya sabian el título, ellos ya saben los títulos de todos los cuentos y ellos eligen un cuento toda la semana." 


\section{Motivación profesional}

Dentro de esta subcategoría, hace referencia a la motivación que tiene un individuo, la cual está determinada por objetivos presentes y futuros relevantes relacionado con una profesión formando parte de los aspectos esenciales que determinan su actitud en general. En este caso ir perfeccionándose en la labor que se cumple como docente en la vida de los/as niños/as, que surge a partir de la implementación de los rincones lectores.

La participación de profesionales de diferentes áreas ha ido aportando diversos conocimientos según su labor profesional, tanto del equipo gestor como del equipo educativo. Una de las principales motivaciones que surgen desde el equipo educativo del J.I.1 es la satisfacción que produce el evidenciar el interés y el disfrute que tienen los/as niños/as al momento de escuchar un cuento, replicando esta misma acción con sus pares,

"El ver a los niños/as más grande imitando como uno cuenta los cuentos, es una experiencia que me toca ver seguido en la hora de extensión, donde los más grandes leen cuentos a los más bebés, expresándose y mostrándoles las imágenes, entonces ahi es cuando uno ve que lo está haciendo bien."

En cuanto a este mismo tema, el J.I.2 manifiesta una sensación placentera y gratitud por todo lo que han ido adquiriendo en torno a su labor profesional desde el comienzo de esta iniciativa. De esta manera, una de sus integrantes señala:

"Es muy notorio el cambio, además al momento de acercarse al rincón, porqué se acercan y exploran, porque les llama mucho la atención y eso nos hace súper felices y nos hace pensar que de alguna u otra manera estamos haciendo bien nuestro trabajo, y bueno-lograr- el objetivo principal de esta iniciativa, que era acercar la lectura a los niños de manera amorosa y por goce."

Asimismo, mencionan que durante el proceso de su formación profesional enseñan diversas estrategias para fomentar la lectura en los niños/ as, sin embargo, al momento de ejercer en los centros educativos, éstas se van perdiendo con el tiempo, porque no se llevan a cabo, debido a la poca dedicación que se le otorga a la lectura en los diferentes contextos educativos. Señalan que, a partir de todo el proceso de creación de los rincones lectores, se le ha dado más énfasis en este tema y les ha significado retomar la importancia de la lectura,

"... uno igual empieza a echar una mirada hacia atrás $y$ decir "si", a mi todo esto me lo enseñaron, pero no lo ponemos en práctica, no lo hacemos o lo hacemos, pero a la rápida, entonces no era la idea, y vuelvo a repetir para mi fue grato porque dije hay tantas cosas que se van perdiendo y que son tan necesarias en los niños."

Desde otra mirada, en relación a los desafíos profesionales las funcionarias plantean, tal es así que dentro del J.I.2 una de ellas señala que desde que se fundó el jardín infantil tenían proyecciones a futuro en relación al fomento lector, sin embargo, no lo habían podido llevar a cabo debido a la falta de organización de la dirección, así menciona:

"Mi sueño de siempre como fundadora, yo creo, era hacer una biblioteca infantil dentro del establecimiento, siempre se lo propuse a las diferentes directoras, siendo ese mi propósito. Gracias a Dios se pudo lograr, pero la idea es que se siga implementando más."

Otra de las motivaciones profesionales de los equipos, es visualizar la proyección que tienen los rincones lectores respecto al trabajo con las familias. El J.I.3 destaca que es importante incentivar la lectura en los primeros años y de esta misma manera realizar un trabajo colaborativo con la 
familia, logrando que este proyecto sea más significativo para toda comunidad educativa. Una de las integrantes destaca que el involucramiento de la familia, al ser positivo genera en ella una motivación desde su labor educativa,

"El hecho de hacer participar a las familias, hace que se sienten parte del jardín, se sienten comprometidos, no tanto por el hecho de que tengamos a los niños acá, sino que ellos ven que hay un trabajo, que va más allá del jardín y que les sirve también, para trabajar con sus niños en las casas."

\section{Estrategias utilizadas en el rincón lector}

En esta subcategoría, se mencionan las diversas estrategias utilizadas por los equipos educativos para resignificar el respeto y cuidado de los RL, comprendiendo también el cómo se usan y se enseña a usar los cuentos que ahí se encuentran. Por otra parte, también se considerará en esta subcategoría las diferentes estrategias de carácter lúdico, que los jardines infantiles fueron utilizando para presentar de una forma atractiva e innovadora la literatura.

Desde el equipo gestor, uno de los integrantes, específicamente E.G.3, comenta que es primordial llevar a cabo estrategias que permitan sensibilizar a los/as niños/as y a sus familias el respeto por el objeto libro. También nos menciona que diferentes agentes de los jardines infantiles han implementado diversas experiencias en relación al cuidado del libro, "Han implementado distintas estrategias, por ejemplo, el hospital del libro, que la familia entienda que cuando un libro se rompa no es reemplazarlo por otro, sino que tener la responsabilidad de colaborar para que se arregle."
Además, al ir analizando las diferentes entrevistas se puede observar un punto en común de algunas estrategias en los tres jardines infantiles, que son: ambulancia y libro viajero. A continuación, se puede observar diferentes formas de trabajar estas estrategias con las familias.

Dentro de los equipos educativos, uno de los agentes señala, que tienen una estrategia específica para los cuentos que están dañados o rotos, en la cual hacen participe al equipo educativo y a los/as niños/as, así lo afirma el J.I.1:

$$
\text { “...tenemos una ambulancia que si se rompe - un }
$$

libro- lo reparan, pero si pasara eso, una tía se pone un delantal blanco y va a buscar la ambulancia y hay que llevar el libro y todos participan, lo hicimos una vez cuando lo inauguraron con un cuento y los niños quedaron bien interesados, pero hasta el momento no lo hemos ocupado."

Siguiendo con la misma idea, otro de los equipos educativos junto con la familia de los párvulos ha sensibilizado respecto de la importancia del cuidado de los libros, replicando la misma estrategia que el jardín infantil anterior, así lo menciona el J.I.2:

"...tuvimos que hacer un trabajo con ellos y con las familias, para explicarles que los libros no se rompen, que los libros se cuidan y asi llevar a cabo el tema de la ambulancia, que cuando se rompe el libro, lo llevan mediante la ambulancia."

Como nos señala este agente, esta estrategia permite que el libro sea trasladado por los/as niños/ as en un "vehículo" hacia un sector específico de la sala, donde se cuentan con distintos materiales que permitirá poder reparar el libro. Mediante el juego simbólico los párvulos podrán realizar acciones de “curaciones" para poder reparar el libro. 
También el J.I.3 nos ha comentado sobre una experiencia relacionada al cuidado del libro incorporando a la familia en este proceso, que han surgido a partir de este proyecto, por ejemplo, cuando nos cuenta que:

"Un niño rompió el libro y después llega el papá y le dice mire papá esto ocurrió con este libro, pregúntele qué pasó y el niño responde "yo lo hice tira", bien y ¿Qué podemos hacer?, ¿Cómo lo podemos arreglar? lo podemos pegar o lo podemos arreglar, "sî" dice el niño, "perfecto", se lo pueden llevar para la casa papá, "si" dice, no importa no compre uno nuevo, tráigalo, aunque sea parchado, pero tráigalo de vuelta arregladito, lo mejor que pueda."

De esta forma se observa que los tres jardines están preocupados, mediante esta experiencia de reparar los libros, el que los/as niños/as y sus familias puedan ir aprendiendo acerca de la importancia de mantener el cuidado de éstos y a su vez saber que no se pueden romper, puesto que, es un material que entrega amor, conocimientos y experiencias gratas.

Otra estrategia, que se ha llevado a cabo es el "Libro o Cuento Viajero", que tiene como finalidad trabajar colaborativamente junto a la familia, para incentivarlos a leer y así ir creando un espacio íntimo de encuentro entre los/as niños/ as con el adulto. Luego de vivir esta experiencia las familias comentan mediante este recurso las emociones y percepciones que surgieron desde la lectura, así nos comenta el J.I.2 "Ahora lo que ellos están trabajando en casa es el Cuaderno Viajero, donde se llevan un libro a elección, y ellos son quienes relatan el cuento al niño y escriben en el cuaderno las percepciones." El J.I.3, en relación al tema del fomento de la lectura, utiliza esta misma estrategia, enviando éste a la casa, propiciando el cuidado del objeto libro “...la idea es que se fomente desde la casa el cuidado de los libros, el cuento viajero consiste en que se manda dos veces a la semana a distintos niños, la mamá le lee el cuento, le dice que se cuida, no se rompe, y lo que el niño entendió sobre el cuento se queda registrado en el cuaderno."

Es decir, este jardín infantil con esta estrategia busca incorporar a las familias enfatizando el cuidado de los libros y la lectura, "Esas son formas de unir a la familia al proyecto, la familia está involucrada en esto." Haciendo énfasis en el cuidado de los materiales y el realizar la lectura desde el disfrute y placer de compartir este momento.

De esta manera, esta estrategia permite ir acercando a los/as niños/as y sus familias a adentrarse en los diferentes cuentos que se encuentran en cada uno de los niveles, mediante diversas experiencias con los párvulos dentro la rutina diaria, como también en actividades extra programáticas con los adultos, con la finalidad de lograr resignificar la lectura en los/as niños/as. A partir de lo anterior el J.I. 1 da a conocer que se ha dado a conocer el proyecto en reuniones de apoderados, comentando:

"Estamos con el tema del cuento viajero, ellos saben que contamos cuentos, de hecho, hemos tenido reuniones y actividades donde se narra un cuento y a ellos, les ha gustado mucho y van conociendo los cuentos que se encuentran en el jardín, la idea es ir de menos a más, y en conjunto avanzar en la importancia de la lectura de los niños."

Se observa, por tanto, la preocupación de no sólo pasar los cuentos para que se los lleven a su casa, sino también de modelar a las familias, respecto de cómo llevar a cabo la lectura en voz alta. También, los jardines infantiles señalaron que han implementado en su rutina diaria otras estrategias asociadas a la promoción de la lectura 
en los rincones lectores, tales como: el Kamishibai, títeres (dedos, marionetas, sombra y guante), dramatizaciones, cuento con dedos, susurradores y cuento eje.

En relación a la última estrategia, el J.I.3 explica que los niños/as son los encargados de escoger un libro del Rincón Lector, el cual es trabajado de diversas formas durante la semana. En esta experiencia participan tanto los párvulos como el equipo educativo, con la finalidad de que ellos/ ellas puedan ser parte del proceso de selección y también para favorecer la forma de comprender el cuento a partir de las distintas experiencias y también darle su propio significado. Este mismo jardín infantil una de las personas entrevistadas comenta:

"Nosotras trabajamos el cuento eje, esta semana tocaba "Niña bonita", y ese cuento lo escogen el día viernes. Entonces lunes, martes y miércoles lo trabajamos de diferentes maneras. El lunes, por ejemplo, lo trabajamos con títeres, el martes la lectura con el cuento en sí, el miércoles lo actuamos, como lo hizo la tía con algún accesorio y jueves ellos lo actúan. Ese es el cuento eje, el mismo cuento que ellos escogen el día viernes lo trabajamos toda la semana."

Por otra parte, dentro de este jardín infantil, debido a la gran cantidad de niños/as, se hace complejo poder iniciar el momento de la lectura y llamar la atención de todos/as por lo que se utilizan diferentes objetos, los cuales resultan llamativos y despiertan su interés para poder reunirse y comenzar el momento del cuento, este agente alude:

"Hay treinta y dos niños por sala, pero nunca están los treinta y dos, hoy hay veintinueve, entonces cuesta captar la atención, es por ello, que hay diferentes estrategias, no usamos muchas cosas, porque desvía la atención, por ejemplo, tenemos los sombreros y también utilizamos cintas. (....) también usamos un tambor, puede ser un tambor que tú lo golpeas, ya saben que es la hora del cuento, o una campana lo que sea, tú utilizas diferentes estrategias, que ellos sepan que vamos a sentarnos o se van a tirar en el suelo."

La misma entrevistada señala que el espacio también es importante prepararlo, y eso implicó tomar decisiones y realizar modificaciones

"Antes de la implementación, no teníamos la goma eva, teníamos colchonetas de estas de pasto sintético, (...) se acostaban y ponian almohadones o se sentaban en una silla, como ellos quisieran. $Y$ ahi comenzaba la narración de diferentes formas, porque yo podía ocupar (...) un peluche, cualquier cosa que yo tuviera más a mano y le contábamos el cuento."

Esto último, también permite visualizar, que además de marcar el momento del cuento a través de una señal, y de preparar el espacio para que se ubicaran en forma cómoda, también seleccionaron recursos que se vincularan a los cuentos que iban a narrar.

El participante del E.G.1, se refirió a las estrategias implementadas en los Rincones Lectores, comentando que parte de los jardines infantiles le han mandado evidencia fotográfica sobre algunas de las actividades, donde en ellas destaca la actividad del J.I.1 "nos mandaron una foto de un libro en especifico "La tortilla corredora" donde los niños hacian panes, entonces vincularon el tema del libro con una actividad práctica." A raíz de ésto, este mismo jardín menciona que desde esta actividad, se pudo incluir a otro agente de la comunidad educativa y la experiencia vinculada al fomento lector tuvo una mirada más amplia, se logró incorporar aprendizajes significativos de distintos ámbitos, "Hemos hecho el libro de la tortilla, donde invitamos a la manipuladora de alimentos del jardín infantil y se invita a los talleres de cocina." Esto permite evidenciar que los rincones lectores permiten integrar de mane- 
ra transversal aprendizajes de todos los ámbitos, lo que pasa por las decisiones pedagógicas de los equipos.

El J.I.1, comenta que otra de las estrategias, que para ellos ha sido relevante al momento de iniciar la lectura de un cuento, es la utilización del lenguaje verbal y no verbal, sin utilizar objetos o vestimentas, para de esa forma captar la atención de los/as niños/as, más bien pone énfasis en la utilización de un lenguaje kinésico y fonético frente a los párvulos.

"Yo utilizo mucho mis expresiones, trato de ser bien expresiva al momento de contar una historia, siempre busco la forma de encontrar la atención de ellos, de repente no es necesario tener que disfrazarme para hacerlo, el solo hecho de mostrarles otra cara y te pares y muevas los brazos y tengas otras posiciones u otras posturas, ya te toman atención, la expresiones de tu cara y tu cuerpo dicen muchas cosas, entonces los niños se sienten interesados, trato de siempre priorizar que los niños estén atentos, busco la forma si me tengo que parar, me tengo que parar en la mesa yo lo hago, bajar o subir la voz el jugar con los tonos es algo que capta totalmente su atención."

Es decir, existe una preocupación por poner en práctica diversas estrategias para que estén escuchando la lectura o narración del cuento.

\section{Percepción del efecto de los rincones lectores en las comunidades educativas}

Esta categoría se entenderá por las variadas formas en que los participantes, tanto del equipo gestor como del equipo pedagógico de los jardines infantiles, tuvieron en relación a todo lo vivido a partir de la implementación, y cómo esto ha ido generando cambios en las comunidades educativas.
Desde esta segunda categoría se desprenden cinco subcategorías que presentamos a continuación:

\section{Percepción de los participantes respecto a la implementación del rincón lector}

Desde la mirada de uno de los integrantes del equipo gestor destaca la participación en el proceso de implementación del proyecto el trabajo y asesoría de la Universidad de Valparaíso, a través de la Escuela de Educación Parvularia, sus docentes y las estudiantes tesistas, por resignificar la importancia de la lectura en la primera infancia y compartir sus saberes y experiencias en el tema con los equipos educativos de los jardines infantiles, además, de poder tener un seguimiento del proyecto y realizar diferentes actividades que mantengan el interés por el fomento de la lectura en un rincón agradable para los/as niños/as. Así lo menciona:

"Tener la posibilidad de tener a la Universidad de Valparaiso, que trabaje con nosotros en esto, Patricia Herrera que (...) tiene una experiencia importantísima, lleva camino andado en el fomento de la lectura y ella goza, tú la escuchas y te dan ganas y te motiva a seguir con esto, el haber pensado en ustedes que son tesistas que nos han colaborado, que han participado con nosotros, que vinieron e hicieron el taller, ha sido muy importante, yo creo que no habría sido lo mismo sin la Universidad de Valparaíso, habría sido una vez más entregar material y ahi sabe Dios qué hubiese pasado, mientras que ahora tú te aseguras que se va a proyectar con los años, que va a seguir trabajándose en los jardines y tiene un efecto multiplicador."

Las integrantes del equipo pedagógico de los tres jardines infantiles comentan que tienen una mi- 
rada positiva en torno al proyecto, el que ha sido una instancia enriquecedora tanto para ellos/as, los/as niños/as y las familias.

Participantes del J.I.2, comentan que esta iniciativa fue un gran aporte para ellos en su labor profesional, ya que, mencionan que potenciar el lenguaje es uno de los factores primordiales para desarrollo integral de los/as niños/as, y este proyecto les permitió revalorar la importancia de la lectura en la vida de los/as niños/as.

"... esta iniciativa del fomento lector a nosotras nos llegó como "anillo al dedo", porque al final tú dices, si uno tiene que enseñar tantas cosas, pero uno no debe perder lo fundamental, que es el desarrollo del lenguaje, (...) que es también la socialización con los demás."

Además, les permitió indagar en los cuentos desde el interés propio del niño/a, ya que, al ser algo nuevo e innovador logró captar su atención y el tener los textos diariamente dentro del aula les permite relacionarse de manera más directa con la lectura, conocer no solo cuentos de fantasías, sino explorar e imaginar otra literatura que sea más significativa para los/as niños/as.

"Para los niños yo creo que fue importante, por el impacto que se produce, porque ya al ver un rincón en la sala es distinto, te acerca y te motiva a conocer algo que no teníamos antes, por lo menos el hecho de sentarse y sacar un libro. También ver otra literatura que en su vida no habian visto, ni yo tampoco como educadora, una está acostumbrada al de la Caperucita roja, Patito feo, los cuentos más tradicionales, pero ver otros libros que te acercan a su realidad, su vida emocional, a su vida familiar, eso es mucho más importante que tomar un libro que no tenga mucho sentido, entonces leerles un libro que tenga relación a lo que ellos viven, se les abren un mundo de emociones e imaginación, donde echan a volar su mente y están todo el rato pendiente de lo que se les está leyendo."
Es decir, a partir de la implementación del rincón lector, se ha retomado el amor por la lectura y la importancia de que comience desde la primera infancia, ya que ellos al acercarse tempranamente a la lectura pueden descubrir nuevos mundos y conocimientos, que les genera nuevas perspectivas de conocer y descubrir su entorno, dándole la posibilidad de otras oportunidades y no sólo hacerlo por una rutina diaria, sino desde el afecto y el respeto, desde experiencias lúdicas. "Para todas, este proyecto ha sido bien enriquecedor, por lo menos se trabaja de manera lúdica, entretenida, no por decir "ya hoy nos toca hacer esto", sino que es un tema grato, ya no se trabaja como por rutina."

Otro de los jardines infantiles, señala que este proyecto fue fundamental para tener nuevas posibilidades, permitiéndoles encontrar distintas estrategias de manera de aproximar la lectura a los/as niños/as de forma no convencional, tal como lo indica el J.I.3:

“...cuando nos dijeron de este proyecto fue fantástico, porque dijimos vamos a tener mayores herramientas, para presentar a los niños y realizar otras cosas que no haciamos, comenzamos con las dramatizaciones de los cuentos, y les encantaba, e improvisamos cuentos, más fascinados todavía y ocupamos el titiritero y diferentes formas de que ellos pudieran escuchar un relato."

También, a partir de la implementación de los rincones lectores los/as niños/as van adquiriendo nuevas capacidades de forma progresiva permitiendo reconocer y dar a conocer sus intereses y gustos, como lo comenta el jardín anteriormente:

"La capacidad de poder escoger, de elegir, de tener un libro para él, que no la tenían, que ellos pudieran elegir, esto quiero leer. Fomentar la autonomía y que ese libro, es lo que él está escogiendo y eso quería escuchar." 
De esta manera recalcan lo positivo que ha sido este proceso y lo significante que se ha vuelto en la vida del equipo pedagógico y de los párvulos, ya que, la iniciativa de los/as niños/as ha sido gratificante.

Por otra parte, se menciona que esta iniciativa ha sido importante ya que, busca encantar a los/as niños/as abarcando los niveles de sala cuna hasta transición, de esta manera permitiendo poder ampliar el desarrollo del lenguaje ya sea, verbal o no verbal, así también el desarrollo de distintos ámbitos, planificando experiencias que sean relevantes para los párvulos.

"Yo creo que fue bueno, ya que se fomenta desde pequeño a los niños que tengan inserto el tema de la literatura, el cuidado de los cuentos, que se pueden trabajar experiencias pedagógicas a través de los cuentos, reforzar harto el vocabulario, el lenguaje, la expresión, el desarrollo cognitivo, hasta el espiritual del niño, en las experiencias que sean significativas, lo emocional también."

Sin embargo, también señalan que para llevar a cabo lo dicho anteriormente, se requiere de un cuidado, tanto del mobiliario y especialmente de los libros, es por ello, que deben poner énfasis en la valoración del libro como tal. Y una de las entrevistadas, del J.I.1, agrega, que desde esta iniciativa ha sido importante para el desarrollo integral de los/as niños/as que se encuentran en condiciones de mayor vulnerabilidad, permitiendo que todos los párvulos tengan el derecho al acceso a la educación, que entregue oportunidades y que sea de calidad. Igualmente, otra entrevistada del J.I.2, comenta que las familias han tenido una buena recepción al proyecto, ya que, ven en éste una gran oportunidad para generar un cambio positivo en la vida de los/as niños/ as, puesto que, los ven felices y maravillados con las experiencias que se crean a partir del rincón lector.

A través de estas entrevistas, se pudo deducir que el rincón lector aportó en su labor pedagógica, ya que, mencionan que, si bien ellos conocían la parte teórica acerca de la importancia de la lectura, sin embargo, al momento de llevarla a la práctica las experiencias eran monótonas lo que generaba el poco interés de los/as niños/as, pero a partir del proyecto lograron adquirir nuevas estrategias que enriquecieron su labor pedagógica en relación a este tema J.I.1 menciona:

"Es como una herramienta fuerte, porque hacía falta algo asi, nosotros teníamos el conocimiento de la importancia de la lectura, pero nos faltaba la herramienta de cómo encantar a los niños en este tema, ya que el interés siempre ha estado de parte de los niños/as, es uno el que no lo ha potenciado."

Los participantes del J.I.2, enfatizan en otro punto importante, que radica en la pérdida del interés a la lectura en la actualidad, debido, en parte, a la llegada de la tecnología en la vida de los/ as niños/as, siendo los mismos adultos quienes fomentan su excesivo uso, perdiendo de vista el sentido de acercarlos la lectura, como una fuente de información válida y necesaria. Este nuevo rincón lector permite que los párvulos puedan acceder a libros con historias que pueden llegar a ser relevantes para ellos, pudiendo encantar desde la primera infancia el gusto por la lectura.

"Claramente si hubiese tenido la oportunidad de tener un rincón lector, donde se propicie de manera grata la lectura, como lo tenemos hoy, quizás sí me sentiría más atraída a la lectura de cuentos. Porque sé que es importante leer todos los días, aparte como ahora la tecnología nos hace retroceder un poco en ese sentido, uno no lee, solamente observa el teléfono, entonces, por 
ejemplo, una copucha las lee, pero lo que es una noticia o algo importante, realmente no se da el valor de leer."

A partir de esta iniciativa, el mismo equipo pedagógico del J.I.2 mencionan que han descubierto nuevas maneras de trabajar con niños/as que tienen dificultad en el ámbito social y conductual, nos comentan que han tomado decisiones erróneas por falta de conocimientos y debido a la selección de cuentos se dieron cuenta que podían haber colaborado de mejor manera en la conducta de los párvulos y en su desarrollo integral.

Desde la lectura, los/as niños/as pueden sentirse identificados a través del relato de éste y así poder tomar conciencia de sus actitudes y poder generar un cambio, "Mira hay momentos en que uno dice -pucha no haber empezado antes. -" $\mathrm{Al}$ respecto agrega "De repente lo conversamos con las tías, el año pasado habia un niño que era súper violento, y ya no sabiamos qué hacer con él, que hacerle, que inventar con el niño." A partir de esta situación que comentan, los agentes de este jardín infantil se dieron cuenta del efecto transformador que puedan generar los libros de manera transversal, pero en este caso, fue respecto a la conducta de los/as niños/as, así mismo agrega "haber implementado este tema antes, habría sido una buena estrategia con él, porque nosotros ahora tenemos niños que son inquietos, que pelean y la lectura nos funciona súper bien." De esta manera consideran la lectura como una estrategia fundamental para poder ir realizando un trabajo progresivo que permiten a los/as niños/as poder cambiar su conducta a partir del contacto con los libros, también alude a las diferentes emociones que puede tener el/la niño/a, permitiéndole sentirlas, reconocerlas y expresarlas y de esta manera ir construyendo su identidad mediante las historias que escuchan " hay hartos libros que te enseñan a controlar tu rabia, entonces como lo hubiéramos utilizado con él y se sintiera más identificado y apoyado por nosotros y es por esto que nos ha servido harto este año."

\section{Aportes del rincón lector en las comunidades educativas}

Esta categoría se definirá como contribuciones que han surgido desde la implementación del rincón lector a las diferentes comunidades educativas de los tres jardines infantiles, desde dos perspectivas, equipo gestor y equipo pedagógico. Desde la perspectiva del equipo gestor, específicamente E.G.3 alude a que un aporte fundamental del proyecto, es potenciar el trabajo colaborativo con la familia, ya que, cumple un rol fundamental al momento de iniciar y acercar la lectura en la primera infancia, además de realizar un trabajo en conjunto con el jardín infantil, con el propósito de que puedan adentrarse en el mundo de lectura, desde el disfrute y el goce, y así propiciar el querer repetir esta experiencia.

"Te permite hacer un trabajo que integra a la familia y cuando la familia efectivamente se involucra nos beneficia a todos, porque alguien a lo mejor que no tenía acercamiento con el mundo de la lectura se puede comenzar a encantar, puede entender porque es importante, puede apoyar a sus hijos/as, al jardín, porque en el jardín también se hacen bastantes experiencias con ellos digamos."

Desde el inicio del proyecto, este agente comenta que se ha visto un efecto multiplicador, evidenciando como las familias se ha ido involucrando logrando cautivar el interés por la lectura, tanto en los párvulos como en sus vidas.

Este mismo entrevistado, nos señala que han existido diferentes instancias, donde se involucró de manera directa a la familia y así responder de manera oportuna y eficiente a las necesidades 
de los/as niños/as con recursos que son de fácil acceso para quien requiera realizarlas. Una de las instancias fue la iniciativa de las estudiantes tesistas por realizar un taller donde se compartieron diferentes estrategias con el objetivo de resignificar la lectura dirigido a las familias, equipos pedagógicos y al equipo gestor de este proyecto.

"El taller de promoción de la lectura con las familias, bueno además invitarlos a ser socios de la biblioteca, hablar en las reuniones acerca de cómo acercar la lectura en la primera infancia, eso también ayudó bastante, ver que con elementos simples se puede seguir fomentando la lectura, la imaginación y fue súper importante para nosotros también ese aporte que hicieron ustedes." (EG3)

A partir del taller que se realizó en la "Biblioteca Pública Vicente Huidobro" de San Antonio se pudo percatar de que las familias no conocían la nueva biblioteca y su cantidad de libros que son de libre acceso, además existen espacios que brindan comodidad para realizar una lectura ya sea individual o grupal, debido a esta instancia, las familias pueden identificar cuáles son los lugares que permiten el acercamiento al fomento de la lectura, además de conocer sus gustos a la hora de escoger un libro, enfatizando que la lectura es para todos independiente de la edad, etnia y cultura.

Por otro lado, desde la perspectiva de los jardines infantiles J.I.1 y J.I.2 destacan la oportunidad que les brindaron a partir de este proyecto, el poder asistir a diferentes instancias tales como, conocer museos, asistir a la biblioteca de Cerro Alegre, talleres y capacitaciones sobre la importancia de la lectura. También nos comentan de un taller que se realizó en la biblioteca municipal, el que generó que pudieran conocer este nuevo espacio y aprovechar la oportunidad de poder visitar estas dependencias tanto las familias, niños/as como el equipo educativo. Todas estas experiencias, les permitió salir de su zona de confort y poder indagar en este tema, para contribuir al desarrollo integral de los párvulos para nutrirse de conocimientos acerca de los beneficios y estrategias en relación a la lectura. Así lo menciona el J.I.1:

"Fue una experiencia muy grata y diferente, porque nunca habiamos sido capacitadas en este aspecto y también a veces uno no le da la importancia y se empieza a capacitar en otras cosas, a estimular de otra manera el desarrollo y el aprendizaje de los niños/as."

Asimismo, J.I.1 agrega que a través de la lectura en un rincón lector se genera un espacio íntimo que propicia el diálogo entre quien lee y quien escucha, es una situación de bienestar al interior de las familias, lo cual potencia aspectos relevantes en el desarrollo afectivo, como lo son el apego y vínculo que se da entre los padres y sus hijos, como también, entre las familias y el equipo educativo, al compartir las experiencias que se van dando en los hogares.

Un aporte significativo en el J.I.2 y J.I.3 fue esta motivación de los equipos educativos para involucrar a las familias en este proceso, reuniendo recursos para ambientar y generar un lugar agradable y de calidad. Esto se evidenció con el entusiasmo que tuvo la familia por contribuir al desarrollo integral de sus hijos y favorecer la vida de ellos/as a través del fomento de la lectura una de las respuestas que permite observar tal aseveración:

"La familia, por ejemplo, nos ayudó harto, nosotras igual tuvimos que hacer harta gestión, bueno estos jardines infantiles no cuentan con muchos recursos, con los mismos apoderados juntamos dinero y todo para poder avanzar en este proyecto poder implementar nuestro rincón y la verdad en este sentido nos han apoyado mucho." 
Los dineros recaudados se utilizaron para comprar materiales con los cuales se han hecho diferentes recursos literarios para utilizar con los/ as niños/as de los niveles educativos en el rincón lector, además la familia está consciente que este proyecto contribuye al desarrollo de sus hijos/as de manera significativa por lo que se han visto presente a la hora de colaborar en distintas actividades.

“... hemos preparado láminas para el Kamishibai, hemos hecho títeres con las familias. Esas son formas de unir a la familia al proyecto, la familia está involucrada en esto. La participación de la familia ha sido muy buena, del momento en que responden y cumplen con los plazos, es porque están interesados, muestran el interés y están muy contentos en la metodología que se les está enseñando a los niños."

Participantes del J.I.3 comentan que este proyecto les ha permitido poder afiatarse como equipo pedagógico y tener un objetivo en común que vendría siendo el cuidado y organización del espacio, que les permita tomar buenas decisiones en consideración a lo que es mejor para los/as niños/as en relación a este tema.

"Con el equipo, estamos como bien afiatadas lo que es la mantención de la biblioteca, a tenerlo limpio. A poder relatar cuentos, todas relatamos durante la semana, todas tenemos el espacio para poder relatar, teniendo como foco principal a los niños."

\section{Importancia de la temática en la selección de libros}

Esta subcategoría, se define al significado que le brinda el equipo gestor y equipo educativo a la selección de libros que se encuentran dentro del rincón lector, porque para conseguir integrar la lectura en la vida de los/as niños/as y convertirla en un instrumento que invite a la imaginación, exploración y al goce, tomando en consideración las características, habilidades y la edad de los párvulos, siendo fundamental que la historia sea de calidad con un contenido adecuado que transmita algún conocimiento y reflexión para el crecimiento personal, ya que, no todos los libros cumplen la función que nos proponemos darle en la educación.

En relación a la temática el equipo gestor aborda distintos puntos acerca de la importancia que tiene la selección de libros, como lo menciona E.G.3, los jardines infantiles antes de la implementación de los rincones lectores no contaban con una variedad y cantidad suficiente de libros con contenidos relevantes para los/as niños/as, sino más bien el acercamiento más frecuente de los párvulos con la literatura eran los cuentos tradicionales de carácter fantásticos, revistas y diarios, los cuales eran aportados por las familias. Además, E.G.1, cuando realizó visitas previas a la implementación del proyecto tenían carencia en la calidad de los libros, más allá del material sino en su contenido lo cual se debe a la poca información que maneja el equipo educativo de cada jardín infantil.

"Nosotros nos dábamos cuenta que antes de habilitar los rincones lectores uno iba a las aulas y los libros que tenian los niños no eran de buena calidad no solo del papel más bien de lo que entrega el libro, no eran historias que fueran significativas para los niños. Eso les faltaba a los jardines infantiles y por medio de las capacitaciones se les pudo abrir un poco más el espectro y asi saber que hay otros libros con mejor calidad literaria y que puede generar un involucramiento tanto de los niños/as como de las familias para ver el fomento lector como un tema importante".

Una de las integrantes del J.I.2, comparte la idea que tiene E.G.2 mencionada anteriormente, 
donde agradece el poder conocer y acercar las diferentes variedades de libros que permiten poder ir adquiriendo nuevos conocimientos y sensaciones a las que ella no estaba acostumbrada a trabajar, debido al poco acceso que tuvo tanto a nivel personal como profesional, así lo menciona:

"Ver otra literatura que en su vida no habian visto ni yo tampoco como educadora, una está acostumbrada al de la Caperucita roja, Patito feo, los cuentos más tradicionales, pero ver otros libros que te acercan a su realidad, su vida emocional, a su vida familiar eso es mucho más importante que tomar un libro que no tenga mucho sentido."

Para que exista una buena literatura se necesita indagar y conocer autores, referentes e ilustradores importantes que se destaquen por generar libros de buena calidad y con temáticas variadas y relevantes, E.G.2 añade "... la calidad de literatura en el mundo de la literatura infantil, hay buenos diseñadores, ilustradores hay buenos cuentistas, editoriales es muy bueno comprar libros, comprar inmobiliarios para incentivar la lectura desde los niños y la educadora de pároulos." Además, a partir de su experiencia personal y profesional enfatiza en las buenas editoriales de los libros, donde sugiere “... el DEM es un libro Zig- Zag donde son muy obvio los libros, mientras que CARÉ es mucho mejor y hay un montón de editoriales que la misma patricia nos sugirio."

Otro de los puntos importantes para la selección de libros, es tener en consideración contar con una gran variedad de libros que permitan poder abordar diferentes temas que sean significativos para los/as niños/as y se relacionen con sus vivencian, así lo respalda E.G.1 "donde existe una coherencia muy interesante donde es importante que los libros tengan diversas temáticas, por ejemplo, hay unos que hablan de los miedos, animales etc. todos esos temas y ayudaba de cómo saber abordarlos." Un ejemplo de ello, es lo que menciona una de las integrantes J.I.3, quien a partir de la literatura que se encuentra dentro del rincón lector, ha podido trabajar diferentes ámbitos de aprendizaje mediante de un tema de interés del niño/a,

"...que pasa que los niños con TEA, hay uno por ejemplo que le gusta mucho los dinosaurios, entonces se trabaja en base a los dinosaurios que él tiene, ya sea, lo lógico matemático con el dinosaurio, vamos avanzar tanto con el dinosaurio, vamos a misión espacial, vamos a dejar el dinosaurio en tal sector, ¿Dónde está el dinosaurio?, es de su interés el dinosaurio, entonces a él se le tienen cuentos con dinosaurios."

Otra experiencia que ha surgido en relación a la temática de los cuentos, respecto a las prácticas realizadas luego de la implementación del rincón lector, es la que menciona el J.I.2, quienes pudieron reflexionar desde su quehacer pedagógico, considerando éste como una estrategia primordial para abordar diferentes temas, tanto emocionales como conductuales, así lo comenta una de las participantes:

"Ahora tenemos niños que son inquietos, que pelean $y$ todo y nos funciona súper bien, pero ese niño era, incluso estaba medicado y todo iba al psiquiatra, entonces nosotras deciamos pucha haberlo tenido antes, a lo mejor le hubiera gustado eso, hubiésemos partido por ese lado, con los libros. Lo habríamos hecho mejor con él si hubiéramos empezado con el tema de los libros, porque hay hartos libros que te enseñan a controlar tu rabia, entonces como para habérselo contado a él y se sintiera más identificado y apoyado por nosotros."

Con respecto a la selección de los cuentos, uno de los agentes, específicamente E.G.2, comenta que existen temas que son delicados para abordar en la primera infancia, como lo son: la muerte y la separación debido al alto impacto que puede causar en los/as niños/as, siendo la literatura es una estrategia apropiada para poder llegar a 
ellos/as de una manera más sensible, logrando que puedan asimilar este tema de la mejor forma posible. De esta misma manera, el J.I.2, hace alusión a que los cuentos cumplen una labor fundamental a la hora de presentarlos a los/as niños/ as, puesto que, las diversas formas en que se utilizan para acercar la lectura a ellos/as, se hace de manera lúdica con la finalidad de que se disfrute y sea significativo, y a partir de esto permitir que se sientan identificados con cuentos que abordan temáticas específicas, por ejemplo “...ese cuento que el niño no sabe pronunciar las $r$, te desafio a no bostezar, y todos son súper significativos los niños se sienten identificados."

\section{Comportamiento de los/as niños/as, en relación al objeto libro a partir de la implementación del rincón lector}

Esta subcategoría se entiende por las diferentes conductas de los/as niños/as y los cambios con respecto a la interacción que ellos/as presentan con el objeto libro. Los análisis fueron elaborados a partir de la observación que realizó el equipo pedagógico respecto al antes, durante y después del proceso de la implementación. Además, la opinión de participantes del equipo gestor.

Todos los jardines infantiles pertenecientes a este proyecto, han realizado un trabajo previo sobre el cuidado y respeto hacia los libros, inculcando de esta manera un significado y valor para éstos. Los equipos pedagógicos realizan un trabajo colaborativo con la comunidad educativa, a partir de las diferentes estrategias que ya se mencionaron anteriormente, relativa al uso y cuidado del libro. Ellas señalan que han observado un cambio relevante en los/as niños/as, así lo plantea el J.I.1 "...hasta el minuto no ha pasado que lo han roto pero tenemos una ambulancia que si se rompe lo reparan."
En este sentido, los párvulos han ido tomando conciencia de manera progresiva, acerca de la importancia del libro, tal como se observa en la siguiente cita, "ahora lo toman con cuidado saben que tienen que tomarlo con las manos limpias se acuerdan de la receta y saben que no hay que romperlo."

Sin embargo, también reconocen que no ha sido fácil, ya que, mencionan que hay conductas que se han normalizado a través del tiempo y que es necesario abordar y modificar. $\mathrm{Al}$ respecto otra funcionaria de éste mismo jardín señala:

"Ha costado un poquito por el tema que acá antes igual habian libros y como le contaba los niños lo veían como un juguete, pero poco a poco se han ido familiarizando con esto y lo van cuidando de mejor forma, pero de principio cuesta, es un proceso."

Con respecto a esta inquietud del cuidado del material, el J.I.2 plantea:

"Con relación a los niños y a este espacio y lo que conlleva de éste, se ha notado un cambio, por ejemplo, en el cuidado de los cuentos y del espacio en sí, nosotras igual desde un comienzo les explicamos que este material es nuestro tesoro valioso, que tenemos que cuidar porque es para nosotros, que lo ocupamos diariamente, entonces si les llega a pasar algo no lo podríamos ocupar. Y para ellos igual han ido tomándole poco a poco importancia y valor a cada material, al momento de tomarlo y manipularlos."

Por otra parte, señalan que “... estar pendiente de que los niños no los vayan a estropear o no los vayan a romper, entonces también se les explica que hay que cuidarlos, tratarlos con amor, hacerles cariño." A partir de estas citas, se infiere que por parte del equipo pedagógico ha habido un constante trabajo con los/as niños/as mediante la comunicación asertiva, con el fin de ir formando una actitud de buen uso de los cuentos. 
Se entiende la actitud de los/as niños/as, desde su actuar lúdico y su relación con el objeto libro desde esta condición, ya que, en general el vínculo que ellos/as tienen con los cuentos es desde la exploración, sin considerar que detrás de este objeto libro, hay una historia contenida que invita a descubrir y compartir junto a otros. Retomando el planteamiento de este mismo jardín infantil, comentan, "tomaban el libro y lo tiraban por ahi."

Otro de los aspectos importantes a considerar, dentro de los comportamientos que se observan en los/as niños/as es la edad, hay una diferencia entre lo que pasa en los párvulos de sala cuna, con respecto del nivel medio, ya que, así lo comenta una de las integrantes del J.I.3, "ellos no leen, pero ven las imágenes y se lo imaginan y ellos lo relatan." Sin embargo, también mencionan que "los más grandes ya saben, de tres a cuatro años, pero el chiquitito de dos a tres años, los sacan, pero no los hacen tira, los sacan, los desordenan, los hojean y ahi andan con ellos." Con respecto a lo planteado anteriormente el J.I.1, se suma a las palabras dichas anteriormente y agrega que "los niños que son más grandecitos cuentan en sus casas las experiencias que pasan acá en el jardín y los papás siempre nos comentan lo que ellos le contaron." Es por esto, que es importante que la experiencia con el cuento sea significativa para los/as niños/as, con el fin de puedan internalizar y transmitir la satisfacción de la escucha de la narración desde su vivencia. Además, cuenta que, desde la implementación del rincón lector, los párvulos al visualizar el nuevo espacio con los diferentes mobiliarios y materiales que son nuevos y llamativos, en ellos/as surge la iniciativa de acercarse de manera natural y autónoma, así lo afirma una de las integrantes de este jardín infantil "a penas ellos ven la biblioteca se acercan para sacar un cuento, lo cuidan al momento de girar las páginas, es un proceso que de apoco lo hemos logrando." Asimismo, mencionan que estas experiencias, van potenciando el desarrollo del lenguaje, ya que, esto permite ampliar el vocabulario a través del lenguaje oral y por esto, es importante realizar acciones desde la primera infancia. Así lo señala el J.I.2:

"Al momento de que los niños descubren que es lo que haremos, qué es la lectura de cuentos, lo escogen y se preparan para escucharlo, durante este se comienza a generar una especie de conversatorio con ellos, donde van compartiendo lo que van sintiendo, interactuando también entre ellos mismos o con nosotras."

Por ende, considerar la edad de los párvulos es un factor importante al momento de tomar decisiones respecto al uso de las estrategias para cada uno de los niveles que respondan a las características propias de su desarrollo.

Lo que se acaba de señalar, es corroborado también por E.G.3, integrante del equipo gestor, quien hace referencia a que "si bien el libro en un principio es un juguete para el niño, el adulto lo tiene que tratar con tanto amor para que el niño entienda que es un tesoro preciado." Lo que hace referencia a la importancia que tiene el modelaje del adulto, ante el niño/a como una forma también de instalar hábitos lectores.

Otro de los cambios significativos que han sido evidenciados en los jardines infantiles por parte del equipo educativo del J.I.2, es el reconocimiento que los/as niños/as le otorgan al rincón lector, debido a que antes de la implementación no tenía un lugar definido para la lectura, sino más bien, era un espacio donde se encontraban diversos materiales tales como: cuentos, revistas, diarios y papeles, siendo estos tres últimos los que se utilizaban para hacer actividades de motricidad, como rasgar, y es por esto, que los/as niños/ as confundían el verdadero valor de los cuentos que en ese momento se encontraban en el espa- 
cio, pero luego de la implementación, se volvió significativo debido al trabajo colaborativo del equipo pedagógico que se dio durante el proyecto, ya que, se encargó de otorgarle la importancia correspondiente al rincón lector y es por esto, que ahora los/as niños/as saben y reconocen que ese lugar es para pasar un momento agradable entorno a la lectura y ellos/as se acercan a buscar cuentos, así lo señalan las participantes "saben que solo se encontrarán con cuentos en ese espacio y nada más que pudiera distraerlos como otros materiales, si ellos quieren otro material tienen que dirigirse a otro mueble."

También destacan que el uso y cuidado de los cuentos como objeto libro ha mejorado por parte de los/as niños/as, donde observan que ellos/as al tomar un libro no solo se dirigen al rincón lector, sino que a otros sectores del aula.

"Toman un libro a veces se van a una casita de muñeca que tenemos acá arriba, entonces toman un libro y si quieren estar solos se van a la casa de muñeca y lo empiezan a mirar y que los cuidan mucho, y que esperan el momento del cuento."

A raíz de esta cita, se desprende que los/as niños/as buscan un lugar cómodo, acogedor y agradable donde se sientan a gusto para disfrutar de la lectura. Además de esto, dan cuenta que ellos/as crean su propia historia a través de su imaginación y exploración que realizan al momento de escuchar o leer un cuento.

A partir de todo lo mencionado anteriormente, uno de los jardines infantiles hace referencia a todo lo que se ha llevado a cabo en el proceso de implementación del proyecto, lo cual ha generado grandes cambios positivos para la comunidad educativa tal y como lo señala el J.I.3 "todas esas cositas pequeñas han hecho empezar a tener cariño, respeto, amor por el libro y no tanto como por la lectura, sino de lo que significa el libro."
5. Actitudes y emociones de los/as niños/as a partir de las experiencias en los rincones lectores.

Esta subcategoría, alude a las percepciones que tienen los equipos pedagógicos y equipo gestor en relación a lo que experimentan y expresan los/as niños/as, a partir de la implementación de los rincones lectores, debido a que se han generado diferentes situaciones de aprendizaje, las cuales han logrado cambios importantes en ellos/as.

Un integrante del equipo gestor en relación a las actitudes y emociones que presentan los/as niños/as, comenta que, a partir de la visita realizada a estos jardines infantiles, pudo evidenciar que, debido a este proyecto, los párvulos se han ido sumergiendo en un ambiente que les resulta muy atractivo, donde él/ella puede imaginar, sentirse participe, llevarlo a la vida cotidiana y de esta manera poder ir conociendo el mundo que les rodea. Para que esta experiencia sea más significativa, debe enfocarse siempre en el agrado que sienta el/la niño/a al escuchar el relato, ya que, esto gatillará en que quiera repetir la experiencia tanto en el jardín infantil como en el hogar. Así lo señala E.G.3 “...te das cuenta de que ellos lo están disfrutando y que ellos después son capaces de recordar y de compartir con sus familias."

Otro agente del equipo gestor destaca a este proyecto, como una gran oportunidad de acercar a los párvulos que no tienen las mismas oportunidades de acceder a cuentos de calidad que permitan poder dejar huellas en ellos/as a través de las diversas emociones que experimentan, debido a diferentes factores. En relación a este tema, uno de los integrantes del equipo pedagógico, específicamente J.I.2 comenta “...el niño tiene otro estímulo quizá ese niño no tenga la posibilidad de ver el libro tan cercano de forma tan amable, porque esas pri- 
meras emociones, aunque no sepa leer después les quedan a los chicos en su recuerdo." Además, agrega “...es necesario que los niños exploren los libros porque te hacen pensar, imaginar." Por ende, es importante que se acerquen a la lectura, puesto que, les permite potenciar su pensamiento divergente y convergente.

A partir de la lectura, los párvulos pueden ir comprendiendo su entorno familiar y social, ya que, al escuchar una narración, se pueden sentir identificados con el relato, generando una conversación mediada en relación a la vida del párvulo y de esta manera, ir conociendo su propia historia y la de los demás. A partir de este punto J.I.1 menciona:

"...estamos contando una historia y los niños comienzan a contar lo que les pasa a ellos en su vida cotidiana, con la mamá con el papá, ya que, se identifican en los cuentos y utilizar las preguntas que permitan ser más abiertas que le permitan conocer el punto de vista de cada niño, ya que, no todos piensan de igual manera y viven distintas situaciones algunos coinciden y otros no."

Los/as niños/as a partir de la experiencia con el cuento pueden ir adquiriendo nuevas habilidades, capacidades y/o aprendizajes. Tal y como nos señala E.G.3:

“...la autonomía de poder decir, porque la biblioteca está a disposición de ellos todo el día, y el enfoque hoy en día es que sea el protagonista y la posibilidad de elección, hacia allá vamos caminando, que siempre ese ha sido el enfoque de Educación Parvularia."

En relación a este mismo punto, un integrante del equipo educativo, agrega que debido a este rincón los párvulos han tomado un rol activo en cada experiencia, ya que, se les ofrece una cantidad de libros y ellos/as son quienes deciden que leer, además de poder dialogar en relación a la narración, así lo destaca J.I.2:
"Los niños puedan debatir, escuchar o compartir sus experiencias a partir de la lectura de los cuentos, todo esto es relevante porque uno le da como el pie a que ellos se vayan convirtiendo en protagonistas de este rincón lector."

También uno de los integrantes del equipo pedagógico, plantea que a partir de la incorporación de los libros en la rutina diaria ha permitido ir desarrollando el área cognitiva de ellos/as, puesto que, invita a los párvulos a ir reflexionando, generar nuevos conocimientos, y potenciar la concentración, así lo señala J.I.2 "activar la parte cognitiva, son niños que los ayuda a pensar, que estimula la parte neuronal, para poder pensar, para poder desarrollarse." En estas experiencias los/as niños/as se muestran interesados por la actividad, esto se debe a que ésta es de su agrado, lo que genera que realicen preguntas que invitan a reflexionar y generar nuevos conocimientos, así lo señala J.I.1 "Nosotros percibimos mucha atención concentración, también están atento, asombrados y preguntan porque les gusta mucho preguntar." En relación a esto mismo, otro jardín infantil enfatiza que la narración debe ser lúdica, pues así los/as niños/as van conociendo y desarrollando el lenguaje tanto oral como gestual, así lo comenta J.I.3 "varios de ellos han desarrollado su lenguaje verbal, cuando se le cuenta un cuento es mejor expresarlo con el movimiento de uno."

Con respecto al lenguaje, un integrante del equipo gestor, destaca que es uno de los factores más importantes en el desarrollo de los párvulos, ya que, a partir de éste podemos potenciar otras áreas, este agente comenta que es relevante realizar un acercamiento al lenguaje de manera que las experiencias que se planifiquen sean positivas, tal como señala E.G.3:

"El lenguaje es el motor central de todo lo que nosotros hacemos, éste nos permite abarcar todas las otras áreas y es primordial, y que mejor que hacerlo desde el 
goce, del disfrute y es ahi lo medular diría yo con esta propuesta del proyecto de fomento lector, entender ese enfoque principal que es a través del goce de la lectura como tú puedes llegar y que es lo importante marca la diferencia."

En consiguiente, un jardín infantil comenta que, debido a la lectura el/la niño/a se va desarrollando de manera progresiva. Un aspecto fundamental del lenguaje es conocer nuevas palabras con su significado, las cuales son usadas en la vida cotidiana, como algo natural e implícito, J.I.2 alude "adquiriendo un mejor vocabulario que es súper importante la lectura, a través de eso ellos tienen un mejor lenguaje, mejor vocabulario, más expandido."

Asimismo, gracias a los textos los/as niños/as van desarrollando la participación en cada experiencia de manera espontánea, a partir de una dinámica que es de su gusto e interés. Así lo menciona J.I.3 "Están todos atentos mirando la mayoria, siempre son muy participativo al escuchar el cuento, opinan y preguntan, la mayoría participa porque les gusta bastante." Esto es compartido por una integrante del equipo educativo del J.I.2, quien agrega que los/as niños/as participan más de las experiencias lectoras, debido a que los libros son llamativos, tanto por su estética como también por su contenido. En relación a lo último, se debe a que se sienten identificados con las situaciones que ocurren en la narración, lo que da paso que puedan participar, preguntando, respondiendo y/o contando experiencias personales.

Los/as niños/as, también a partir de estas experiencias van desarrollando el área afectiva, ya sea con la familia o con el equipo pedagógico. En relación al equipo pedagógico.J.I.1 agrega:

"Se ha visto cambios significativos en la personalidad de los niños/as, se ven más seguros y felices, donde uno les dedica más tiempo, yo creo que para ellos es bastante enriquecedor compartir ese momento con ellos y enlazarlo con el tema afectivo."

Además, una de las integrantes de los equipos educativos destaca que, a partir de la narración, ella puede acercarse a las realidades de los párvulos, ya que, ellos/as cuentan cómo se sienten a partir de experiencias que han tenido en el hogar, las cuales en algunos casos son negativas, lo que le permite poder contener, conversar y guiarlos para poder favorecer su bienestar a partir del afecto, tanto corporal como verbal, que le entrega, así lo plantea el J.I.2:

"Entonces con esto te abre la posibilidad de acercarnos mucho más a ellos, y desde otra mirada, a través de la lectura ellos mismos van contando solitos porque se sienten identificados con los personajes o con la historia en sí."

También, se fomenta la interacción entre los/as compañeros/as, ya que, a partir de este rincón, pueden ir vinculándose unos a otros y de esta manera, ir construyendo vínculos afectivos. Con relación a esto, J.I.3 alude:

"Lo principal es la interacción entre ellos, ellos se juntan ahi, tienen total libertad, en sacar el libro que a ellos les interesa, ellos llegan escogen su libro, se juntan de dos o de tres y escogen estar en la biblioteca y así se van conociendo y formando amistades."

Los tres jardines infantiles, han señalado que uno de los temas más destacados a la hora de hablar del desarrollo de los/as niños/as ha sido el aspecto relacionado a la emoción, a partir de esta nueva experiencia con los libros en el rincón lector. Un integrante del equipo pedagógico, nos menciona que los cuentos que se encuentran en este espacio, son generalmente relacionados a las emociones, lo que permite abrir un mundo de ideas, imaginación, expresión, conversaciones de sus experiencias, y a partir de los libros los/as 
niños/as pueden contar lo que les está pasando, permitiendo poder acercarse a ellos/as, ya que, a través de la lectura van relatando porque se sienten identificados con el personaje o con la historia. En relación a lo señalado anteriormente J.I.2 comenta:

"Los cuentos hablan de muchas cosas, aspectos emocionales de la rabia, pena y felicidad. Emociones que ellos no saben cómo expresar o no saben lo que sienten, o cosas como que los niños se portaron mal con los papás, cosas que se viven en la vida diaria y que ellos no saben cómo abordarlo, pero gracias al cuento ellos pueden decirlo."

Este agente, agrega que, a partir de las experiencias lectoras, los párvulos han ido mejorando de manera progresiva la manifestación de sus emociones. Además, comenta que es gratificante poder ver a los párvulos felices, ya que, cambió la concepción que tenían del objeto libro, J.I.2 destaca:

"En el caso de los niños, han tratado de manifestar mucho mejor sus emociones, entonces a la vez, tú vas trabajando distintas áreas y distintos temas con ellos y con eso se van abriendo mayores posibilidades de que ellos puedan crear, imaginar, desarrollar vivencias personales como también inventarlas. La emoción al verlos contentos y motivados es gratificante, porque uno ve que ellos están en otra sintonía y ya no es como "que fome, ya vamos a leer."

En relación a la expresión de las emociones, un integrante del equipo pedagógico, destaca que, a partir de esta experiencia, ha podido ir trabajando con los párvulos situaciones que han sido y son un desafío tanto para ella como para los/as niños/as, lo que ha permitido que puedan reconocer las emociones y de esta manera aprender a autorregularlas J.I.2, cuenta: "...pasa mucho con niños que tenemos ese tipo de problemas, que no saben cómo expresar su rabia y se genera un caos. Entonces esto nos ha servido también para calmar la ansiedad de los niños mucho, porque antes teníamos muchos problemas con niños que se exaltaban muy rápido por cualquier tema y con el equipo nos costaba mucho abordarlo."

Esto ha permitido que los/as niños/as, sean capaces de poder reconocer lo que les está ocurriendo, conversar y llegar a una solución, dejando de manera progresiva los desbordes emocionales, generando un ambiente grato, tanto para sus compañeros en el aula, como también sentirse bien consigo mismo, así agrega:

"Entonces nos ha servido para apaciguar esa ansiedad de ellos, de que estén más tranquilos, ya no se siente como ese ambiente denso, ahora es mucho más relajado, más tranquilo donde al final todos lo disfrutamos y lo pasamos bien que es lo importante."

Integrantes de otro jardín infantil, se suman a lo anterior y comentan que los párvulos se sienten identificados y reflejados con los personajes de los relatos a partir de las emociones y situaciones que comparten con él/ella, esto ha permitido poder vivenciar y reconocer diferentes emociones, considerando que los cuentos son una herramienta pedagógica primordial a la hora de poder identificar éstas, así lo dice J.I.2:

"Mira a los niños, por ejemplo, cuando se enojan con algún cuento porque les molesta algún personaje, ponen cara (de enojo), o se ponen contentos, o se rien, se rien mucho, sobre todo de los cuentos de los niños de las emociones, el tema del niño que no sabe pronunciar bien las palabras, entonces también "Quiero comedte", y andan todos así como comedte, entonces se rien harto."

En relación a esto mismo, J.I.1 destaca “....receptivos y atentos, expresan sus emociones a través de ges- 
tos, por ejemplo, si la historia cuenta que está enojado o sorprendido ellos imitan eso, entran en el cuento a partir de lo que están escuchando." En este punto los cuentos son una estrategia fundamental a la hora de conocer lo que están viviendo o sintiendo los/ as niños/as y así poder ir acompañando en todo momento este proceso, para que sea significativo para ellos/as.

Lo mencionado anteriormente, se relaciona de manera directa con la selección de cuentos que se encuentran en este nuevo espacio, ya que, a partir de una narración, se pueden abordar temáticas relacionadas con sus vivencias y como se sienten a partir de cada situación expuesta en la narración la cual se asemeja a su realidad, tal y como señala J.I.2 “...la selección de los cuentos del rincón están orientados a ese tema lo que permite que los niños puedan ir asociado las historias con su propia vida, a su experiencia haciéndolos más significativos.”

Los/as niños/as, mediante una experiencia grata con los cuentos van generando un gusto por la narración, esto incide directamente en lo que se busca lograr a partir de los libros, que es generar de manera progresiva el gusto por la lectura, fomentando ésta desde la primera infancia. Los párvulos a partir de la curiosidad, la cual expresan de manera gestual o no, van a ir leyendo o solicitando que se les lea para poder conocer el mundo que les rodea, así lo comenta J.I.3:

“...querer saber más, y ¿Qué viene más.?, la ansiedad, me hacen preguntas, comienzan a interactuar, ¿Qué pasa?, ¿Qué viene después? Y ahí tú le vas dejando la incógnita a ellos, de ¿Qué pasará? Las emociones se visualizan en los gestos, en las expresiones, tú notas altiro las expresiones y la ansiedad que ellos presentan y que viene ¿Y?"
III. Proceso de implementación de los rincones lectores en los jardines infantiles

Esta categoría, a través de distintos puntos aborda cómo el equipo gestor y equipo pedagógico han vivido las diferentes etapas en relación a la implementación del rincón lector en los distintos jardines infantiles. Desde esta tercera categoría se desprenden siete subcategorías que se presentan a continuación:

\section{Experiencias previas en literatura infantil}

Esta subcategoría, define las vivencias en relación a la literatura, ya sean, en el ámbito personal y profesional durante sus vidas de los distintos participantes de los tres jardines infantiles.

Una parte considerable de los tres jardines infantiles, menciona haber tenido poco acercamiento con los cuentos durante su infancia, sin embargo, existen participantes que sí tuvieron experiencias en este ámbito. Así lo señala el J.I.2 "era como el libro mensual que te hacian leer en el colegio y después te hacian la prueba el libro." Se puede inferir desde esta cita, que la lectura desde las instituciones educativas era un acto impuesto, primando la evaluación, por sobre una experiencia grata y significativa, quitándole el valor que conlleva la lectura en la vida de las personas. Con respecto a la cita anterior, otra participante del mismo equipo educativo, menciona que dentro de su núcleo familiar no existía interés por la lectura, por lo tanto, no se transmitió el gusto y placer por ésta. No obstante, comenta que en el ámbito escolar se fomentaba la lectura en un horario y días determinado, el cual era acompañado de una evaluación. 
"...en el colegio nosotros teníamos la hora de lectura donde se tenía ese enfoque de leer todos los días, pero era más de una mirada pedagógica o evaluativa, entonces nos implementaron que teniamos 15 minutos de lectura todos los días, y bueno mi profesora del colegio igual nos hacía escoger o llevar un cuento y leerlo, era como algo que fomentaba el colegio, entonces yo siempre quede inculcada con eso."

A partir de su previa experiencia con la literatura, luego de la implementación del rincón lector, le permitió reflexionar en cuanto a las diversas oportunidad y beneficios que conlleva la lectura, concluyendo que lo más importante es adentrarse a ésta, desde una experiencia donde prime el goce, la libertad y el disfrute, dejando de lado la imposición y aspectos formales, como lo es la evaluación.

Una integrante del equipo pedagógico, comenta que también tuvo una experiencia positiva en relación a la narración de cuentos en la primera infancia, donde destaca la figura de su abuelo quien le relataba historias, él vivía lejos, sin embargo, esta integrante comenta que ella le gustaba viajar, porque sabía que su abuelo la esperaría con el cuento, así lo señala J.I.3 "les voy a contar un cuento de mentiritas" y ese era muy tradicional en él, en que todos los días, él se sentaba con nosotros y cuando estaba en el atardecer a contarnos cuentos." De esta cita, se desprende lo importante de una buena mediación en la narración al momento de encantar a los/as niños/as y así fomentar la lectura, ya que, como comenta, gracias a su abuelo pudo tener una buena experiencia, que deja huellas hasta el día de hoy "a mí me encanta ir para allá, porque contaba puras mentiras y era entretenida la historia que contaba y uno se imaginaba las cosas que nos contaba y siempre me gustó mucho la literatura, mucho." Agrega, que, al momento de ingresar al sistema escolar, el gusto por la lectura iba aumentando de manera sucesiva a medida que conocía nueva literatura "Yo estudié en una escuela municipal, que tenía biblioteca y de pequeñita yo me iba a la biblioteca a buscar libros de cuentos y poemas." Mediante esta experiencia la cual fue de manera libre y lúdica, ella pudo ir apropiándose de los libros y hacer de la lectura algo significativo en su vida, además hoy en día reflexiona acerca del rol que tienen los adultos con los/as niños/as, en relación a este tema, tal y como lo reafirma "Esa es una de las experiencias que tuve desde pequeña y que me quedó hasta adulta y por eso yo trato de, a los niños, traspasárselos a ellos, porque desde pequeñito tú vas haciendo grandes lectores, adultos lectores."

Una participante del equipo pedagógico del J.I.2, hace hincapié en un punto relevante con respecto al concepto de "libre", quien recalca que es importante que la primera infancia tenga un acercamiento a la lectura desde algo no impositivo o bajo la concepción del conductismo, es decir, no imponer una lectura, con el propósito de conseguir algo, en este caso una buena calificación, sino más bien, proponer a los/as niños/as que mediante la lectura de carácter libre, pueden adquirir conocimientos y sensaciones de bienestar, tal y como lo menciona:

“...acercar la lectura desde más chiquititos, desde el goce, desde los tres primeros años. Porque si tú le empiezas a regalar libros cuando los niños ya están leyendo obligatoriamente en el colegio, la lectura mensual, que al final tiene una nota y es una obligación $y$ les regalas libros es como fome, es como "iay!, el libro", como que le tomas un poco de recelo."

Otra integrante del equipo educativo, comenta que de igual manera que la agente anterior, también tuvo experiencias en el colegio en relación a la evaluación correspondiente a la lectura de un libro, donde no fue significativa en su infancia que fuera significativa en relación a este tema, J.I.2 comenta "Yo leía los libros que tenía que leer para 
estudiar, por imposición, pero nunca nada más concreto nada por el goce que es lo que buscamos ahora."

De este mismo modo, en relación a su experiencia personal una de las integrantes del J.I.3, senala que desde su infancia tampoco tuvo un acercamiento directo con los cuentos, debido al poco acceso y conocimiento que se tenía de éstos. Por lo tanto, le otorgó un valor significativo a la variedad de cuentos que conoce hoy en día.

"En realidad, los cuentos ahora se han transformado, son más didácticos, son más llamativos para los niños, antes no eran tan así, más allá de lo que te enseñaban en el colegio, que era de otra manera, no tan libre, o tan especial que lo toma uno, era más por una nota, esa es la diferencia que hay ahora y esos vínculos con los cuentos, no habia mucho antes."

Otros agentes, mencionan que tuvieron únicamente un acercamiento en la etapa universitaria, sin embargo, esta fue muy breve, sin profundizar en el tema, debido al poco tiempo que se encuentran en las casas de estudio, así lo menciona J.I.1:

"Mi experiencia previa creo que no es mucha, fuera de lo que pude haber estudiado en la universidad, que fue algo bien breve y pincelada a lo mejor, lo cual no pasa más allá de conocer algún autor o cómo trabajar en los diferentes niveles la lectura con los niños."

Dentro de esto mismo, un integrante de otro jardín infantil, agrega en relación a este tema, que, si bien la literatura infantil fue abordado al momento de su formación profesional, con el tiempo lo que le enseñaron se va perdiendo, debido a que la lectura, no es trascendental como estrategia pedagógica, así lo explica J.I.2:

"...cuando uno estudia, que te enseñan tantas cosas, pero a la larga eso se va perdiendo un poco con el tiempo. Tú al llegar a trabajar a un establecimiento te pierdes como del foco, entonces uno piensa que tra- bajando otras cosas que son importantes, uno deja de leerles a los niños deja que ellos también se acerquen a la lectura."

Cabe destacar, que los agentes de los equipos pedagógicos de forma personal han tenido la iniciativa de poder ir perfeccionándose en relación a la narración de cuentos, así lo mencionan dos participantes J.I.1 y J.I.3, quienes comentan que han asistido a talleres de cuenta cuentos, donde destacan que participar de estas instancias les ha permitido poder adquirir nuevos conocimientos y estrategias que permitan acercar la lectura de una forma más agradable, lúdica y novedosa.

Todos los jardines infantiles, comentan que antes de ser parte del proyecto han intentado poder tener una biblioteca en el aula, sin embargo, llegan a la conclusión de que ésta no ha funcionado, así lo señala J.I.1 “...éramos "nulas" en este tema, porque siempre hacíamos bibliotecas en la sala, pero nunca funcionaban, pedíamos a los apoderados libros y revistas para contribuir a lo que esperábamos de la biblioteca." A esto, se suma a las palabras otro jardín infantil, quien comenta que su biblioteca tenía un gran número de revistas, las cuales estaban junto con los cuentos, debido a que no existía un rincón específico de lectura. Los/as niños/as al ver el material de motricidad fina junto con el de lectura, confundían ambos y realizaban acciones que dañaban el libro, tal y como lo menciona J.I.2 “... habia revistas y papel de diario, que a veces lo ocupábamos para rasgar, entonces confundían los cuentos con eso y hacían lo mismo." Esto generaba que los párvulos no conocieran los cuentos por su contenido literario, lo que provocaba el poco interés de ellos/ as por la literatura infantil.

Integrantes de los tres jardines infantiles, aluden a que, si bien no tenían mucho conocimiento acerca de cómo realizar un trabajo en relación a la lectura para fomentar ésta en los/as niños/ 
as, destacan que esta oportunidad ha sido positiva para profundizar este tema y trabajar siempre en beneficio de los párvulos, tal y como lo señala J.I.1 “...capacitaciones que han sido mucho mejor y hemos aprendido más como educadores para entregarle una mejor calidad de enseñanza a los niños." Agente de otro jardín infantil, menciona que, debido a experiencias previas con la literatura, las cuales no fueron significativas, se considera una lectora pasiva, sin embargo, comenta que es importante poder acercar la lectura a los párvulos en la primera infancia. Así lo dice J.I.2:

"Para ser sincera, por gusto personal soy mala lectora, pero si considero que es un enfoque súper importante para los niños porque uno le da el énfasis para que ellos puedan crear, soñar e imaginar cosas que no son realidad, pero es maravilloso que vivan esas experiencias."

\section{Percepción del equipo gestor hacia la Educación Parvularia}

Esta subcategoría, se determina por la mirada que tienen los participantes del equipo gestor, acerca del rol que desempeña la educadora de párvulos, con respecto a la importancia que tienen en la vida de los/as niños/as.

Desde el punto de vista del equipo gestor, consideran a la Educación Parvularia fundamental en la sociedad, debido a que las educadoras de párvulos son agentes primordiales en la vida de los/as niños/as, ya que, son las responsables de acompañar y apoyar en los primeros años, los cuales, son esenciales en su desarrollo y aprendizaje convirtiéndose en la base de lo que quieren ser y aprender a lo largo de toda la vida. Con respecto a la implementación de los rincones lectores, aluden a la intencionalidad de los equipos pedagógicos desde una perspectiva emocional para trabajar el tema del fomento lector, sin olvidar el referente de la Educación Parvularia que ofrece un conjunto de fundamentos, objetivos de aprendizaje y orientaciones, para el trabajo pedagógico e implementación directa en el aula, así lo afirma E.G.3 "obviamente tenemos que trabajar- lo conforme nos orientan en nuestro referente que son las $\mathrm{Ba}$ ses Curriculares de Educación Parvularia, donde está el tema de lenguaje verbal y artístico, la verdad es que cruza con todas las áreas."

Por lo tanto, consideran a las educadoras de párvulos como personas fundamentales en el proyecto "Mi Primer Rincón Lector", además, se tomaron en consideración a todo el equipo pedagógico de los tres jardines infantiles, los cuales fueron invitados a diferentes instancias durante la implementación, así lo señala E.G.3 "generalmente se capacitan las educadoras en los jardines infantiles nunca llegan las técnicos y mucho menos al auxiliar de servicio, y en esta oportunidad fuimos con todos los equipos completos así que fue muy especial." A raíz de esta cita, se puede inferir la importancia del trabajo en equipo, que se generó en torno a este proyecto, logrando enriquecer el fomento de la lectura en la vida de los/as niños/as, además, menciona que gracias a las capacitaciones que se realizaron se pudo sensibilizar a todos los agentes de los jardines infantiles, pero que será un proceso progresivo, señalando que "yo siento que el equipo pedagógico tiene ganas de poner en pie este proyecto a ejecutar el fomento lector, pero siempre tiene que ir acompañado y no será fácil."

Otro de los aspectos primordiales, que señala uno de los integrantes del equipo gestor, son las redes que puede generar la educadora de párvulos mediante diferentes acciones para incentivar la participación de la comunidad educativa, con el fin de potenciar y favorecer el bienestar de los/ 
as niños/as desde un enfoque biopsicosocial, a esto hace referencia el E.G.2:

"De parte de la educadora de pároulos y la gente de las comunidades educativas yo veo apoyo, veo que la gente está motivada obviamente no todos se motivan de la misma manera, pero es importante que la educadora se dé cuenta de la importancia de esto."

Siguiendo con la misma idea, E.G.3 agrega que "ellas también te hacen saber que efectivamente para ellos es importante esta oportunidad, entonces están expectantes de que a ellos les toque llevar el texto, entonces se genera un efecto que se multiplica y toma fuerza." Con esto, se puede evidenciar la motivación que tiene los equipos pedagógicos por buscar estrategias que acercan a los/as niños/as a la lectura para que esta repercuta más adelante. Por otro lado, este mismo agente señala:

"solamente el 20\% de las educadoras tienen especialización, también la educadora tiene que ver esto una proyección de su carrera y pueda aumentar su salario gracias a su especialización y así beneficia a los niños y a toda la comunidad."

En relación a lo mencionado anteriormente, se considera como un elemento que fortalece la labor profesional que cumplen las educadoras de párvulos. Las investigadoras se suman a las palabras, dando énfasis en la mención que cursaron "Promoción de la Salud", la cual está estrechamente relaciona al proyecto, puesto que, al fomentar la lectura durante los primeros años de vida de los/as niños/as, se puede desarrollar el lenguaje potenciando lo cognitivo, afectivo y emocional, ya que, son fundamentales para su desarrollo integral, en relación a este punto, el mismo participante señala:

"La otra vez me invitaron a una inauguración de un punto lector en un CESFAM, que trabaja una niña que estudió en la Universidad de Valparaíso y ahi que es como un pequeño hospital, un sector súper grande en Bellavista, yo esas cosas las privilegios y apoyo porque te sientes respaldado, por eso yo digo que hay futuro en este trabajo."

Esto demuestra, que el punto lector no solo se puede trabajar en instituciones educativas, sino también se puede trabajar en diferentes áreas, como lo es el área de la salud.

\section{Proceso previo a la implementación de los rincones lectores en los jardines infantiles}

Esta subcategoría, da cuenta de cómo surge el proyecto "Mi primer Rincón Lector" y como se llevaron a cabo las diferentes etapas desde la perspectiva del equipo gestor y el equipo educativo.

Participantes del equipo gestor, específicamente E.G.1 y E.G.2, hacen alusión que los ejes principales Fundación de Desarrollo San Antonio Siglo XXI que son de carácter social, ambiental y educacional, con respecto a esta última área se han llevado a cabo distintos proyectos, tal como lo menciona E.G.1:

Antes del proyecto de "Mi primer Rincón Lector", desarrollamos un proyecto llamado "Biblioaulas" iba enfocado a los niños de primero ciclo básico, de primero a cuarto básico, en donde establecimos una sala modular, que cumplía un doble propósito darles a los estudiantes un espacio fisico donde tener una sala de clases y a la vez habilitar una biblioteca."

De esta misma manera, E.G.2 agrega que este proyecto se instaló en escuelas rurales, donde se compraron container traídos de Santiago, los cuales fueron modificados y ambientados con la finalidad de crear una biblioteca. 
Debido que las "Biblioaulas", sólo abarcaba los niveles de enseñanza general básica, el equipo gestor vio la necesidad de realizar un proyecto el cual beneficiar a la primera infancia, E.G.1 menciona, que la misión de la Fundación Siglo XXI es vincularse con entidades tanto públicas como privadas, es por esto, que tuvo que contactar agentes de Programas Jardines Infantiles de la Dirección de Desarrollo Comunitario de la Ilustre Municipalidad de San Antonio. Así lo señala E.G.3, que en el año 2018 fue contactada por un agente de la Fundación de Desarrollo San Antonio Siglo XXI, el cual le comentó acerca del proyecto que enfatiza en el fomento de la lectura para los programas de los jardines infantiles. Para este proyecto menciona:

"En primera instancia se decidieron visitas a 6, nosotros tenemos 12 jardines VTF en la comuna. $Y$ en aquella oportunidad solo visitamos 6 porque sabíamos que el financiamiento no cubría para tanta cantidad de establecimientos. De esos 6 jardines se priorizaron 3 jardines infantiles que se le consideraban que eran más necesidad de apoyo para mejorar su gestión técnico pedagógica y ahi fue que se favoreció entonces a Pañud, Bello Horizonte y Mi Mundo de Colores, para que pudieran participar del proyecto de fomento lector con fundación siglo XXI

Este agente, destaca este proyecto debido a que hoy en día el MINEDUC exige implementar en cada una de las aulas bibliotecas, para poder trabajar el fomento lector con los/as niños/as y poder acreditarse con un estándar mínimo de calidad, comenta que les exigen "el tema de infraestructura, que los espacios están habilitados, el mobiliario, los textos."

Para llevar a cabo este proyecto, el equipo gestor busco una asesoría técnica la cual fue impartida por la Universidad de Valparaíso, específicamente por una docente de la escuela de Educación
Parvularia, experta en el tema de la lectura, lo que permitió poder encantar tanto al equipo educativo como al equipo gestor en la importancia de éste, E.G.1 "fue bastante positivo para detonar un poco el involucramiento de las educadoras y técnicos para utilizar el material." Además, les entregó diversas estrategias a los equipos pedagógicos para poder acercar la lectura desde una experiencia grata y significativa. A raíz del contacto establecido del equipo gestor con esta casa de estudio, resultó una alianza estratégica la cual benefició a toda la comunidad educativa a través de diferentes gestiones que se dieron, tales como: visitas, talleres y capacitaciones, donde se profundizó acerca de la importancia, beneficios y estrategias que conlleva a la lectura en cuanto a la selección de textos y materiales para propiciar el rincón lector.

Con respecto a lo anterior, los equipos pedagógicos de los jardines infantiles, beneficiados por este proyecto, también dan cuenta del proceso que vivió cada institución de manera singular y significativa. Una de las integrantes del J.I.1, destaca la importancia que tuvo para ella, asistir a diversos encuentros donde pudo resignificar acerca de la lectura, además de ir adquiriendo nuevas prácticas y herramientas en su quehacer pedagógico, así lo menciona "cuando empezamos a ir a las capacitaciones logré descubrir cosas que no conocía una de ellas es como presentar los libros a los niños dependiendo su edad."

Una de las integrantes del J.I.3, señala que es primordial que existan proyectos que inculquen la lectura en la primera infancia, integrando tanto a los/as niños/as como a la comunidad educativa, es por esto que menciona:

“... fue muy grato para mí cuando me avisaron que podíamos postular a este proyecto porque una de las cosas más importante para los niños es despertar la 
imaginación, la curiosidad a través de la lectura y fomentar a través del cuento, fomentar la lectoescritura."

Asimismo, el J.I.2 señalan haber estado muy entusiasmadas por el hecho de ser parte de este proyecto, ya que, las diversas instancias a las que fueron invitadas les permitieron perfeccionarse en torno a la lectura. Dentro de este jardín infantil, la familia también fue considerada donde se les informó acerca de esta iniciativa para poder contar con su apoyo, señalando "...cuando hicimos la inauguración del fomento lector, también les explicamos, participaron, les mostramos fotos, después tuvimos una exposición de fotos también y en las reuniones de apoderados también hemos contado."

\section{Desafíos y temores}

Esta subcategoría, se define por los obstáculos y desafíos que surgen a partir del proceso de implementación de los rincones lectores, tanto para el equipo gestor como para el equipo pedagógico, debido a experiencias previas en relación a la lectura.

Con respecto a este punto, un integrante del equipo gestor, específicamente E.G.1, comenta:

"Uno de los principales temores fue que la inversión de tiempo y recursos se diluya, ese fue el principal temor, ya que, uno hace las cosas con cariño y pasión, a parte que, hay involucradas varias instituciones, como la Fundación que pone los recursos, Universidad de Valparaiso que pone el recurso humano y la asesoria técnica, también está el tiempo de la organización de Programa de Fardines Infantiles."

Por lo tanto, se desprende que el mayor temor de este agente fue que todo lo invertido durante el proceso de tiempo y recursos por parte de las instituciones no tenga proyecciones en un futuro.
Además, otro de los factores predominantes a la hora de hablar de este tema, es el poco conocimiento que se tiene de la importancia y beneficios de la lectura, ya sea, en la primera infancia como a lo largo de la vida. Así lo señala E.G.2:

"La ignorancia de no saber la importancia de que es esto y no valorar eso, yo creo que es el gran desafio porque la gente entiende que "ah biblioteca, hay que leer" son frases típicas, pero no es tan así."

Lo que se desprende de esta cita, es que la mayoría de la gente no valora la lectura en sus vidas, debido a experiencias que no fueron gratas para ellos/as. No obstante, la acción de leer va mucho más allá de decodificar palabras, más bien es una experiencia que permite conocer y adentrarse al mundo de las emociones.

Por otro lado, E.G.3, comenta que varios participantes de los jardines infantiles, manifestaban que el desafío principal de este proyecto, recae en el cuidado del material del cual han sido beneficiados, y como ya se mencionó anteriormente en la subcategoría "Comportamiento de los/as niños/as, en relación al objeto libro a partir de la implementación del rincón lector" los/as niños/ as tendían a confundir el objeto libro perdiendo el valor de éste, "en un principio le tenían terror a entregarle los textos a los niños, porque no siempre se da la oportunidad de tener una colección así, entonces casi que no quieres tocarla para que no se te rompa o algo." De esta manera, este agente, tuvo un rol mediador con los equipos pedagógicos, compartiendo la idea de que los espacios se deben respetar y no deben ser invadidos por otro tipo de material, dando énfasis al libro como un objeto único y valioso, realizando buenas prácticas desde lo afectivo.

Uno de los participantes del J.I.1, respecto a la relación del objeto libro agrega: 
"El principal temor era que no iba a funcionar, que nos iba a costar mucho y que iba a ocurrir lo mismo que ya nos había pasado que los niños iban a romper los libros, por esta razón es que llevo por periodos los libros".

Asimismo, el J.I.2, comparte el miedo de que los libros no sean respetado por los/as niños/as, causando pérdida del material y también señala, que se proponen distintos desafíos con el propósito de velar por la integridad del libro.

"El desafio que hoy en día nos tenemos que proponer como equipo en este punto, es seguir impulsando y potenciando el cuidado del entorno y explicándoles a ellos que todos los materiales que contamos en nuestra sala y el cual fuimos beneficiadas es simplemente para su bienestar y para los niños que vienen a futuro."

Además, otro de los desafíos es poder generar un ambiente de conversación donde se pueda compartir y transmitir a los/as niños/as, el amor y cariño con el que se deben tratar los cuentos. Otro integrante de este jardín infantil, comenta que, a partir del temor, tomaron una decisión:

"Si ponemos un libro lo pusimos con mucho temor, empezamos con uno, después otro, ya después tres libros $y$ así, pero con mucho temor que los fueran a romper, al principio con pocos libros, poco menos los plastificamos con scotch."

De esta cita se infiere, que en esta institución es un proceso progresivo el presentarles más cuento a los/as niños/as, con la intención de que ellos/ as puedan darle significado e internalizar el cuidado del libro.

En relación a este tema, el presentar los cuentos a los distintos niveles es un desafio, ya que, al hacerlo hay que considerar la edad de los párvulos y a partir de éstos generar diversas estrategias, así lo afirma J.I.3:

"Lo que hay que trabajar más es el cuidado de los cuentos que no los rompan y eso es con los dos niveles explicarle que los cuentos son para mirarlos, cuidarlos no romper sus hojas y las estrategias que se usan es reforzar todos los días."

Con respecto al nivel sala cuna, es importante tener presente que los/as niños/as se encuentran en la etapa sensorio motor, por lo que necesitan explorar el mundo a través de sus sentidos, es por esto, que uno de los integrantes del J.I.2 señala "con los más chicos nos cuesta un poquito más y bueno a nosotras también nos da un poco de miedo que los rompan."

En relación al punto anterior, se menciona que se buscaron de manera conjunta distintas estrategias que permiten darle un sentido al mobiliario y a los libros para no considerarlos como un elemento sin intención pedagógica, sino más bien, como una oportunidad para desarrollar diferentes habilidades en el equipo educativo para transmitirlos a los/as niños/as. Por medio de reuniones realizadas con los equipos pedagógicos de los jardines infantiles, E.G.3 alude:

"Compartimos las experiencias y eso sirvió mucho para sacar ideas y todo, y para que tomara más fuerza, yo siento que ahi se produjo el momento de inflexión, donde decir ya perdamos el miedo y las chiquillas mostraron fotos, se dieron cuenta de que si es posible."

\section{Cambios evidenciados durante el proceso de implementación de los rincones lectores}

Esta subcategoría, aborda las transformaciones que el equipo gestor y equipo educativo de los distintos jardines infantiles, han percibido desde 
que se dio inicio al proyecto "Mi Primer Rincón Lector".

En relación a este tema, un integrante del equipo gestor, destaca que, a partir de diferentes reuniones con los tres jardines infantiles, pudo concluir que este nuevo espacio ha sido valorado, entregándole todo el cuidado para que pueda mantenerse durante el tiempo. Tal y como señala E.G.3 "se mantiene en un espacio que es súper respetado, entonces se trata con amor." Además, señala que el proceso de cada jardín infantil, ha sido diferente, gracias a las reuniones técnicas realizadas a partir de este proyecto, las instituciones educativas van compartiendo ideas para fomentar la lectura en el rincón lector, logrando así ir encantando a todo el equipo educativo, para que puedan ir traspasando este sentir a sus diferentes contextos y comunidad educativa, en relación a este tema, agrega "hicimos la reunión y compartimos las experiencias y eso sirvió mucho para sacar ideas y todo, y para que tomara más fuerza, yo siento que ahi se produjo el momento de inflexión."

Integrante de uno de los jardines infantiles, enfatiza que a partir de esta implementación existe una organización del espacio que invita a los párvulos y al equipo educativo, poder encontrar el material y el mobiliario especifico en un sector determinado del aula, el cual los/as niños/ as reconocen como un ambiente que invita a la lectura, tal y como lo señala J.I.1 “ Los cambios para nosotras ha sido mucho mejor, porque se le entrega algo más ordenado a los niños se hace con un tiempo donde ellos pueden sentarse a escuchar el cuento y ellos aprenden." En relación a esto mismo, otro integrante, específicamente del J.I.2, comenta que el cambio que pudo evidenciar a simple vista, es la nueva estructura con la que cuentan hoy en día, ya que, el espacio del aula está condicionado con repisas, libros nuevos y puff, lo que ha permitido poder tener un espacio, el cual se caracteriza por ser acogedor, el cual invita a tener un acercamiento a la lectura de forma interesante.

En relación con este mismo tema, otro integrante de este mismo jardín infantil, comenta que antes de la implementación, si bien contaban con áreas específicas de aprendizaje, no contaban con un espacio único que fomentara el lenguaje. Destaca que a partir de esta iniciativa los párvulos, reconocen este nuevo sector y les es de su interés, así lo comenta J.I.2:

"Pero ahora el ver que es un rincón necesariamente y especifico para el fomento lector, eso les llama mucha más atención de los niños, porque saben que solo se encontraran con cuentos en ese espacio y nada más que pudiera distraerlos como otros materiales, si ellos quieren otro material tienen que dirigirse a otro mueble."

Este mismo agente, agrega pudo observar que desde la implementación del espacio los/as niños/as se sienten parte de este rincón, lo aprecian, comparten entre ellos/as y con el equipo educativo. Para ella es gratificante poder ver este cambio de interacción de los párvulos. En relación al último punto, una participante del equipo pedagógico, específicamente del J.I.3 agrega:

“...ellos se reúnen, es algo que nace desde ellos, es grato y al ser grato para ellos es algo significativo, ellos llegan a contarle a la mamá, que la tía les conto tal cuento, que la tía se puso el gorro, lo sienten como algo mágico."

Otro agente de este jardín infantil, señala que debido a esta implementación pudo reflexionar, que, si bien es importante tener un espacio para poder invitar a los/as niños/as a encantarse con la lectura de cuentos, también es primordial poder ir generando diferentes estrategias que sean del agrado de los párvulos. Así lo destaca el J.I.2: 
“... considero que lo fundamental es tener más implementos o recursos y no me refiero solo a lo material, que por su parte si nos hacía falta porque teníamos siempre los mismos, que no eran para nada novedosos, sino que, como diferentes estrategias para presentarles a los niños la lectura desde un lado más amable donde ellos puedan disfrutar y pasarlo bien al hacerlo."

Además, agrega que es importante este proyecto, ya que, pueden contar y trabajar con libros que quizás no hubieran podido conocer, sino hubiera sido por esta iniciativa.

"En cuanto a los cuentos que llegaron, nosotras estábamos muy felices al ver la variedad de historias o temas que traen consigo, porque no tenemos los recursos para acceder a estas lecturas y ahora que lo tenemos es algo que tenemos que aprovechar y velar siempre por el bienestar de nuestros niños."

Tal y como se señala anteriormente, la noción del objeto libro ha ido cambiado de manera progresiva por parte de los/as niños/as, antes de la implementación no se cuidaba la estructura del libro, ahora a partir de diferentes estrategias implementadas por el equipo educativo, se ha ido tomando conciencia acerca del cuidado de éste, como un bien preciado para el aprendizaje y disfrute. Tal y como lo señala J.I.3:

"...el trato que tienen con el libro fue que al principio no los cuidaban mucho lo rompian, se lo tiraban lo rayaban, lo ocupan para otras cosas, como pistola entonces es un trabajo diario que hemos tenido que hacer, todos los días repetimos y todo el día que se cuidan."

En relación a este punto, un participante de otro jardín infantil, nos comenta que para el cuidado de los libros se tuvo que integrar a las familias, ya que, como bien se sabe las familias son fundamentales, al momento de comenzar a formar hábitos y aprendizajes con los/as niños/as, es por esto, que es primordial poder realizar un trabajo en conjunto, para poder lograr un objetivo que sea significativo y congruente para ellos/as. Así lo comenta J.I.3 "... tuvimos que hacer un trabajo con ellos y con las familias y todo, para explicarles que los libros no se rompen, que los libros se cuidan."

Otro cambio significativo que destacan estas tres instituciones educativas, hace referencia a como las familias se han ido integrando y siendo parte de este proyecto, los jardines infantiles comentan que la relación ha sido mayoritariamente difícil, esto se debe a que los establecimientos se encuentran en sectores de alta vulnerabilidad, lo que genera que no sientan la necesidad de acercarse, ya que, ven al jardín infantil como una "ayuda" para cuidar y entregar los cuidados básicos de sus hijos/as, y no conocen la labor pedagógica que se realiza. Así lo comenta el J.I.1:

“... se está tratando de implementar a la familia porque acá en este sector que es vulnerable, los papas no se acercan mucho al jardín como a la parte pedagógica, son como un poco reacios al tema, se preocupan más si bien de que ellos estén bien, de su bienestar, esas cosas, pero no de la parte pedagógica."

Sin embargo, a partir de este proyecto, se les ha informado a las familias acerca de la importancia que tiene la lectura en la primera infancia, logrando así hacerlos participes mediante distintas estrategias, mencionadas anteriormente en la subcategoría "Estrategias utilizadas en el rincón lector" las cuales los incluye de manera directa, así lo comenta J.I.2 "....incorporar harto a la familia en el proceso del fomento lector, porque ahora las familias también se llevan libros, les cuentan libros, nos cuentan a nosotras que a los niños les encantan los libros."

Así como se involucró a las familias, otro miembro de un jardín infantil nos comenta que, a partir de esta nueva oportunidad, como equipo educativo han ido creando redes e involucrando a la 
comunidad en diferentes actividades en relación a la lectura. Así comparte J.I.3 "hacíamos cuentos y los presentábamos a la comunidad, también trabajo con la comunidad si, y todo relacionado con el medio ambiente."

Un punto relevante, mencionado por una de las integrantes, con respecto a los cambios evidenciados a partir de este proyecto, se debe que hoy en día los/as niños/as han podido ir tomando decisiones en relación a qué, dónde y cómo leer, generando aprendizajes significativos, debido a que forman parte de este proceso, en relación a esto J.I.3 comenta:

“...cuando los niños eligen que es lo que quieren leer, tú le están dando la posibilidad de que sea totalmente autónomo en sus decisiones, porque antes era todo impuesto por nosotras las tías y las opiniones de los niños no eran consideradas, en cambio ahora no, ellos deciden todo, son los protagonistas de lo que ellos quieren aprender."

\section{Seguimiento de los rincones lectores}

Esta subcategoría, se define al conjunto de acciones que se llevan a cabo por parte del equipo gestor, para evidenciar diversas actividades relacionadas al proyecto "Mi Primer Rincón Lector".

Un integrante del equipo gestor, menciona que para hacer seguimiento acerca del proceso de implementación del rincón lector, se realizan reuniones periódicas con todos los equipos pedagógicos tal y como se menciona en la subcategoría anterior, así lo señala E.G.3:

“...nos ponemos de acuerdo y compartimos porque habia jardines que tenían un avance como siempre, hay más velocidad o se les ocurren distintas cosas y entonces hicimos la reunión y compartimos las experiencias y eso sirvió mucho para sacar ideas y todo, y para que tomara más fuerza."
En cuanto a esta cita, se desprende que cada jardín infantil tiene un proceso único en torno a la implementación del rincón lector, debido a las características y contextos en el cual se sitúa cada uno.

Cabe mencionar que el agente E.G.3 realiza visitas frecuentes a las diversas instituciones educativas. Con respecto a este punto, el E.G.1 menciona que "no hemos realizado visitas, pero por lo menos las encargadas del Programa de Jardines Infantiles nos han mandado fotografias de como se ha utilizado el espacio del rincón lector." Es decir, si bien este agente no ha tenido la oportunidad de ir de manera presencial, si está al tanto, de cómo se ha vivido el proceso de los rincones lectores, a través de otros medios como el registro fotográfico. Por su parte, el E.G.2 manifiesta "quiero hacer una visita ... a las aulas, para ver si se están utilizando los espacios, ya que, deben tener una finalidad que se cumpla lo que se empezó hacer en su momento."

Tomando en consideración lo que plantea E.G.1, destaca como un seguimiento importante, la actividad que realizaron las estudiantes tesistas de la Escuela de Educación Parvularia, de la Universidad Valparaíso, denominada "Lectura de cuentos, una oportunidad para fortalecer el vínculo con nuestros hijos/as", lo cual fue una experiencia que sensibilizó a la comunidad educativa y equipo gestor para que este tipo de actividades se sigan repitiendo y así ir resignificando la lectura, logrando que ésta no se pierda con el tiempo. Con las diversas actividades que se han realizado, él afirma que a los pocos meses de haber iniciado con este proyecto ha generado una recepción y efecto positivo logrando cumplir con las expectativas esperadas, tanto para la comunidad educativa de los jardines infantiles, como para el equipo gestor. 


\section{Proyección de los rincones lectores desde la mirada de los participantes}

En esta subcategoría, alude a las diferentes expectativas que tiene el equipo gestor y el equipo educativo en relación a cómo se irá implementando esta iniciativa en diferentes contextos, con el propósito de ir cumpliendo y generando nuevos objetivos para que en un futuro este proyecto tenga trascendencia.

En relación a este proyecto, E.G.2 destaca que se han podido generar distintas redes y actividades que han permitido poder conocer y adentrarse en el tema de la lectura involucrando a toda la comunidad educativa.

"Nos hemos seguido vinculando desde el comienzo con ustedes, en el tema de su tesis lo que permite un correlato de todo, ahora viene la actividad con Mata. Ya estamos en septiembre y empezamos en abril casi todo el año nos hemos ido relacionando."

Para complementar, se suma a las palabras E.G.1, quien plantea la siguiente idea "sería interesante considerar que las actividades importantes como son el día del libro, el día de la Educación Parvularia, podamos vincularnos para poder ir y seguir fomentando la lectura." A partir de esta cita, se desprende el poder seguir masificando la importancia de la lectura en la vida de los/as niños/as.

Con respecto a las proyecciones que se tiene mediante esta iniciativa, E.G.3 espera que se pueda ampliar incluyendo a todos los jardines infantiles VTF, de la comuna de San Antonio, además, añade:

"...el encargado del fomento lector en la biblioteca me dio la información de una línea de concurso con el fondo de cultura para las colecciones de libros. Asi que con esa información finalmente uno se va conectando, va estableciendo redes y con la docente de la Universi- dad, amablemente nos contactamos y nos mandó toda la colección que podíamos postular, de ahi postulé al proyecto, asi que esperamos que nos vaya bien y sino de todos modos la Fundación de Desarrollo San Antonio Siglo XXI también tiene pensado seguir beneficiando más jardines, asi que tiene una proyección enorme."

Las proyecciones que se evidencian por parte de los diferentes equipos educativos, tienen como eje principal potenciar experiencias relacionadas al rincón lector generando aprendizajes significativos en los/as niños/as. En relación a este último punto, el J.I.1 comenta "la meta es que sean capaces de contar un cuento leerlo y guardarlo." Destacan que sería un objetivo primordial que los párvulos puedan incorporar la lectura como un acto cotidiano, que produzca en ellos/as un goce y satisfacción al momento de realizar la narración.

Por otra parte, el J.I.2, lo que espera de esta iniciativa, es que se pueda seguir impulsando y potenciando el respeto y cuidado del espacio del rincón lector y hacerlos consciente que el material les dará la posibilidad de poder ir generando nuevos aprendizajes y experiencias enriquecedoras, tanto para ellas como para los/as niños/ as que asisten a esta institución educativa y los próximos párvulos que se incorporarán en un futuro.

Este mismo jardín infantil, menciona que, desde la implementación del rincón lector, se han realizado muchas lecturas de cuentos, de modo, que el material entregado se hace escaso para generar nuevas experiencias, en consecuencia, de esto, añade “...queremos más libros, ahora que sabemos que está la biblioteca municipal, no sabia nada del lugar, ahi podríamos sacar más ideas de cuentos que se adapten a la realidad de los niños." En relación a la cita, se reflexiona que una de las proyecciones de esta institución educativa es poder generar redes per- 
mitiendo poder acceder a una mayor cantidad de recursos literarios.

Otra de las proyecciones, comentadas es poder distribuir los fondos monetarios que reciben por parte de la JUNJI, para poder obtener nuevos libros para el rincón lector y así ir favoreciendo la lectura en los/as niños/as accediendo a los recursos literarios cuando lo deseen.

\section{La oportunidad, en la ruleta de palabras}

Mediante los hallazgos encontrados en las entrevistas realizadas a los diferentes participantes del proyecto, se pudo establecer una frecuencia de las palabras que más presencia tuvieron en los diálogos que se sostuvieron. Para establecer esta frecuencia se utilizó el programa Nvivo 11, el cual permitió la creación de una "nube de palabras" (Figura 1).

A continuación, se presentará la nube de palabra que es generada a partir del software Nvivo 11, que se realizó a partir de los nodos y subnodos que se plantearon:

Figura 1:

Nube a partir de los hallazgos emergentes

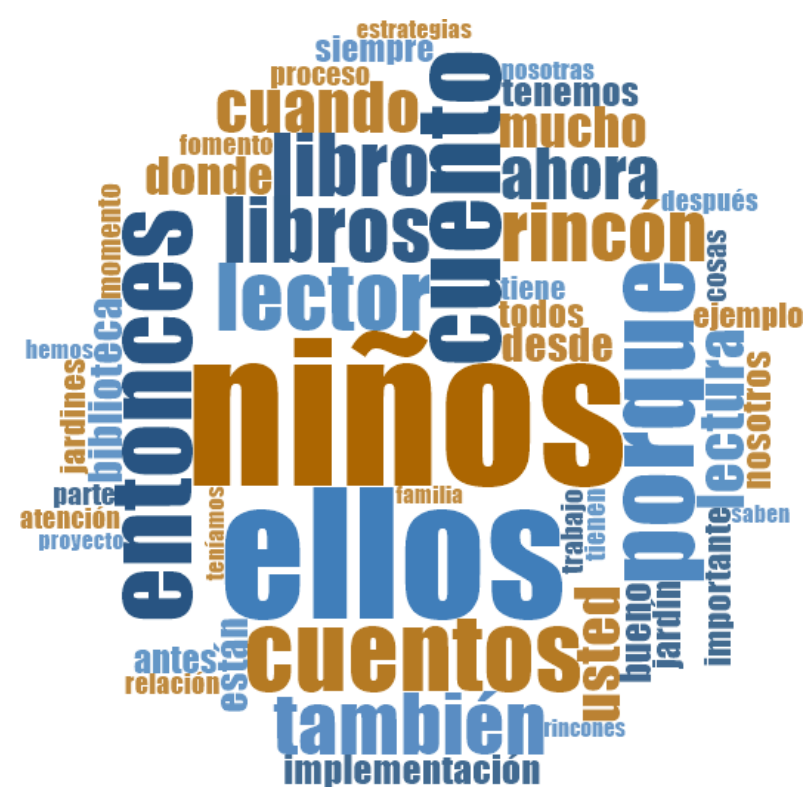

Fuente: Elaboración propia. 
$\mathrm{Al}$ analizar la nube presentada anteriormente, se evidencia que las palabras que tienen mayor frecuencia son: niños, cuentos, rincón y libros, por lo que se infiere que la importancia recae en estos términos, ya que, a partir de este rincón lector se dio paso a la lectura de cuentos y libros, donde los/as niños/as fueron los principales protagonistas de esta iniciativa que se relaciona con el fomento lector.

\section{Discusión}

Los rincones lectores se describen como un conjunto de elementos, en el cual se incluye, tanto el espacio físico con respecto al mobiliario, como también las experiencias y vivencias que emergen a partir de éste, potenciando diferentes áreas para el desarrollo biopsicosocial del niño/a (Durban 2010; Sánchez y Yubero 2015).

Desde la mirada de los entrevistados en este estudio, se agrega que la implementación del rincón lector ha sido una experiencia gratificante para el equipo pedagógico y para los párvulos, ya que, el contar con este espacio propicia un cambio favorable en los/as niños/as, debido a todo lo que se encuentra dentro del rincón lector y las experiencias que surgen a partir de éste.

Desde el punto de vista del equipo de investigación, se consideran fundamentales proyectos de estas características, ya que, a partir de este proyecto específicamente, se pudo crear un espacio dentro del aula para el fomento de la lectura, desde el contexto de cada jardín infantil, brindando la oportunidad de potenciar y generar distintas áreas del desarrollo como lo son: social, emocional, intelectual, físico y cultural. Además, pudieron evidenciar que los equipos educativos estaban profundamente agradecidos y felices por este nuevo espacio y los recursos que se encuentran dentro de éste, en el cual han podido llevar a cabo distintas estrategias pedagógicas en beneficio de los/as niños/as.

Además, para que exista un buen rincón lector se debe contar con un espacio agradable que invite a experiencias placenteras, el cual cuente con una buena iluminación y ventilación, pero por sobre todo que sea un ambiente íntimo y acogedor. En este rincón debe existir mobiliario acorde a las necesidades de cada niño/a, los cuales estén al alcance de todos y les brinde seguridad al momento de estar en el rincón. Dentro de éste, debe haber textos variados y de calidad, los cuales van más allá de lo material, más bien centrado en el contenido de éste, es decir, con temáticas variadas y relevantes que puedan relacionarse con las experiencias personales de cada niño/a.

Swartz (2010) y MINEDUC (2013), hacen referencia al concepto de lectura en voz alta, como una oportunidad para compartir y disfrutar con las demás personas el placer de leer y escuchar una historia o relato, que permite conocer el mundo que los rodea y además potenciar el desarrollo del lenguaje. Transmitiendo a los/as niños/as, que la lectura no solo es aprender información nueva, sino que, va en la forma que cada uno disfrute de ésta.

Desde la perspectiva de los entrevistados, hacen referencia a este concepto como fundamental para fomentar la lectura desde los primeros años de vida, ya que, consideran que una de las cosas que se pueden trabajar, es el vocabulario, el lenguaje, la expresión, desarrollo cognitivo, emocional, y hasta espiritual del niño/a, de este modo las experiencias son más significativas.

Las investigadoras en relación a este tema comparten lo señalado anteriormente, y agregan que 
la lectura en voz alta es una oportunidad enriquecedora, tanto para el que lee como para el que escucha, ya que, se genera una instancia donde ambos pueden compartir vivencias, experiencias o emociones a partir de un relato. También, consideran que al momento de acercar la lectura a los/as niños/as, se debe realizar de manera lúdica, para lograr captar el interés de ellos/as, donde es importante tener presente, la corporalidad, el tono de voz y los gestos de la persona que realiza la acción. Además, el diálogo es fundamental que se pueda dar al interior de las familias, ya que, el impacto que este puede tener enriquece las relaciones afectivas.

Al momento de realizar la lectura en voz alta, es importante considerar la mediación lectora, como lo menciona anteriormente la autora Chambers (2015) en el capítulo I denominado Problematización, quien alude ésta como un aspecto fundamental para acercar la lectura a los/ as niño/as desde el disfrute, el goce y la empatía, con el fin de generar una experiencia grata de esta manera hábitos lectores de manera progresiva.

Fons (2004), señala que el rol mediador debe generar oportunidades donde el/la niño/a se sienta en confianza, valorado y respetado, ya que, es importante entender que son seres únicos, por lo que, debe existir un/a mediador/a que valore esta singularidad. Es por ello, que el MINEDUC (2018), agrega que es fundamental el rol que cumple la educadora de párvulos en la lectura, ya que, es quien podrá presentarle al niño/a diversas experiencias que permiten promover las capacidades y habilidades en el proceso de aprendizaje, en este caso la lectura, todo esto en un ambiente caracterizado por el disfrute y goce.

A partir de los hallazgos encontrados, los entrevistados comentan que en virtud de este proyecto surge una resignificación entorno a la mediación lectora, puesto que, si bien conocen la teoría, en la práctica no lo realizan de manera óptima debido a diferentes circunstancias, tales como: recursos, tiempo, motivación, entre otras. Sin embargo, se fueron dando cuenta que la mediación va más allá de la acción de leer un cuento, más bien es acompañar e invitar a los/as niños/as a adentrarse al mundo de la lectura, a través de un diálogo, de una interacción cercana, que autores como Mata, definen como la creación de un espacio íntimo.

En este aspecto, las estudiantes tesistas aluden al rol mediador como un aspecto relevante a la hora de fomentar la lectura, ya que, son las encargadas de transmitir y motivar a los párvulos para que puedan construir sus propios aprendizajes. Con esto, además, sumergirlos al mundo de la lectura, desde el goce y disfrute, profundizando en la importancia del "qué”, "cómo", "por qué”, “cuándo", "dónde" y "para qué", poniendo énfasis en el sentido de la lectura como puente hacia la elaboración de espacio y mundos singulares desde los primeros encuentros con las palabras.

Román y Cardemil (2014), plantean que los recursos son fundamentales a la hora de acercar la lectura a los/as niños/as, ya que, son herramientas facilitadoras en el proceso de enseñanza y aprendizaje. Además, si se utilizan de manera adecuada, lograrán generar interés en los párvulos y a partir de éste ir fomentando la lectura de manera progresiva.

Los agentes entrevistados, señalan la importancia de implementar y saber utilizar diferentes estrategias, además de valorar el poder ser partícipes de este proyecto, ya que, pudieron asistir a diferentes capacitaciones y talleres, logrando conocer y crear nuevas estrategias para poder acercar la lectura de manera lúdica e innovadora a 
los/as niños/as. Una de las estrategias señaladas frecuentemente hace alusión al cuidado e importancia del objeto libro por parte de toda la comunidad educativa, debido a que es fundamental ir generando conciencia de éste, como un elemento enriquecedor para el desarrollo integral de los/ as niños/as.

Las investigadoras destacan que los recursos, tanto materiales como personales, son primordiales a la hora de presentar la lectura, ya que, permite acercar y encantar a los párvulos al mundo literario. Es por esto, que el docente debe estar en constante búsqueda de recursos y estrategias, las cuales deben ser de carácter creativo, es decir, pensar en ideas nuevas, apropiadas y lúdicas. Donde no se pierda la noción del juego en relación a la lectura utilizando diversas experiencias pedagógicas. Siempre considerando el contexto educativo en el cual se está inmerso.

A partir de lo anterior, generar un impacto positivo en los/as niños/as, logrando así, el deseo de volver a repetir la experiencia, de esta manera se está fomentando la lectura desde los primeros años. Cabe destacar que se deben considerar diferentes formas de utilizar estas estrategias, tomando en cuenta la manera en que ellos/as van aprendiendo, a partir de sus gustos, habilidades e intereses y de este modo, la experiencia será significativa para cada párvulo.

Mata (2009), enfatiza que la lectura es una apertura a muchas cosas, donde no es solamente una cuestión que comienza y termina en un libro, sino más bien aprender a leer y escribir, como una apertura real a otras cosas, tales como: al mundo de la ciencia, de la filosofía, de la vida y social. Asimismo, este referente plantea, que las transformaciones que surgen a partir de la lectura, se entienden como una metáfora, es una puerta que se abre o se cierra para la vida social, en todas sus dimensiones, por lo tanto, garantizar que eso se hace bien, es garantizar que la integración social se va a producir en unas condiciones dignas.

En relación a los hallazgos encontrados en las entrevistas, los equipos pedagógicos destacan que los cambios evidenciados, son netamente positivos, ya que, les permitió poder ir adquiriendo nuevos conocimientos y herramientas, tanto en lo personal como en lo profesional, tomando este último, como un aspecto fundamental para ir perfeccionándose en su quehacer pedagógico y fomentar la lectura en los/as niños/as. Además, de poder realizar un trabajo colaborativo dentro del equipo, con un propósito en común, al momento de planificar y ejecutar nuevas experiencias educativas en relación a este tema. También, reflexionan acerca de cómo la familia se ha involucrado en este proyecto, donde señalan que, si bien ha sido un proceso lento pero constante, han sentido su apoyo, ya que, han participado en diferentes actividades relacionadas al proyecto, logrando poder encantarse con la lectura y considerar ésta como una herramienta fundamental para poder acercarse a los/as niños/as desde el afecto, generar instancias de diálogo y una oportunidad para adentrarse a la lectura de manera compartida. En relación a los/as niños/as, estos agentes enfatizan en que esta iniciativa ha permitido acceder a todos de manera equitativa a conocer, manipular, observar libros, además de vivir experiencias lectoras, pudiendo adentrarse a la lectura como una oportunidad única y para todos/as. Además, se han observado que los párvulos han podido internalizar de manera natural que el objeto libro es una herramienta fundamental en sus vidas, ya que, a partir de éste pueden imaginar, dialogar, compartir, experimentar sensaciones placenteras, entretenerse y conocer. $\mathrm{Al}$ vivir todo esto, han tomado conciencia que el libro se cuida, generando un ambiente de respeto 
ya sea con éste y el rincón, el cual está ambientado para el encuentro con el libro.

En relación a este tema las estudiantes tesistas, a través de las entrevistas y visitas a los centros educativos, han evidenciado, que las transformaciones han sido de carácter positivo, lo cual generó una motivación para ellas, replanteándose la importancia y beneficios de la lectura en los primeros años, y abordar esta temática tanto en la vida personal como profesional.

De esta manera, lo han hecho saber el equipo pedagógico de cada jardín infantil, quienes mencionan que a partir de este proyecto se han generado cambios significativos en la comunidad educativa. Con respecto al equipo, se ve reflejado mediante su rol profesional donde han ido desarrollando diversas estrategias que implica poner en juego elementos curriculares, como la didáctica, objetivos de aprendizaje, espacio educativo, organización del equipo y recursos de calidad teniendo presente las necesidades de los/as niños/ as de su nivel.

Por otro lado, comentan que es importante contar con este tipo de proyectos, puesto que, impactan de manera potente en las comunidades educativas, generando en este caso cambios relevantes en los agentes que la componen. Específicamente esta iniciativa iba en beneficio de los/ as niños/as, ya que, busca un acercamiento de la lectura en un ambiente acondicionado, de manera lúdica y placentera a todos los párvulos sin excepción alguna. Sin embargo, de manera indirecta este proyecto beneficia a las familias, quienes se han involucrado de forma progresiva, pero significativamente, así también los equipos educativos, quienes por su parte han podido ir realizando un trabajo pedagógico desde el enfoque comunicativo, considerando el libro como una oportunidad de acercamiento a los/as niños/as dejando de lado el carácter evaluativo que se solía imponer a éste.

\section{Referencias bibliográficas}

Araos, Ximena Troncoso. 2016. "Descubrir La Literatura Infantil." Atenea 1 (514): 247-61. https://doi.org/10.4067/s071804622016000200247

Belmar, S; Bombal, M; Henríquez, G; Perez, K y Ruiz-Tagle, J. (2018). Plan Nacional de Fomento de la Lectura, Lee Chile Lee: guía para educadoras y agentes educativos. Fomento lector de 0 a 4 años, Santiago. Chile. MINEDUC, JUNJI e Integra.

Chambers, A. (2015). Dime los niños, la lectura y la conversación. México. S.L Fondo de cultura económica de España.

Durban, G. (2010). La biblioteca escolar hoy, un Recurso estratégico para el Centro. España. GRAÓ.

Fons, M. (2004). Leer y Escribir para Vivir. Barcelona. España. GRAÓ.

Mata, J. (2009). 10 ideas Claves. Animación a la lectura. Hacer de la lectura una práctica feliz, trascendente y deseable. Barcelona. España. Grao.

Medina, Alejandra. 2006. "Enseñar a Leer y a Escribir: ¿En Qué Conceptos Fundamentar Las Prácticas Docentes?" Psykhe (Santiago) 15 (2): 45-55. https://doi.org/10.4067/s071822282006000200005 .

Ministerio de Educación (2016). Competencias de la población adulta en Chile: resultados PIAAC. Santiago. Chile.

Ministerio de Educación. (1993). Fondo nacional de fomento del libro y la lectura; ley no. 19.227. Santiago. Chile. Legislación chilena. 
Ministerio de Educación. (2010). Plan nacional de fomento de la lectura, Guía para las Educadoras de Párvulos de los Niveles de Transición. Santiago. Chile. MINEDUG

Ministerio de Educación. (2013). A viva voz Lectura en voz alta. Santiago. Chile.

Ministerio de Educación. (2018). Bases Curriculares Educación Parvularia, Santiago. Chile. MINEDUG.

Ministerio de Educación. CRA. (2006). Ver para leer acercándonos al libro álbum.

Ministerio de Las Culturas, Las Artes y El Patrimonio. "Estudio de Comportamiento Lector: 84\% de Los Chilenos No Comprende Adecuadamente Lo Que Lee” n.d. Accessed January 29, 2021. https://www.cultura.gob.cl/institucional/ estudio-de-comportamiento-lector/

Ordine, N. (2013). La utilidad de lo inútil. Acantilado. Barcelona. España.

Ramírez, E. (2015). La lectura más allá de la letra en la formación de lectores. Investigación Bibliotecológica, 66(29), 7-14. https://doi.org/10.1016/j. ibbai.2016.02.023

Ramos, E. (2009). Plan de fomento de la lectura en Chile: un proceso de construcción participativa. Serie Bibliotecología y Gestión de Información.
45, s/v,19., Disponible en http://eprints.rclis. org/13323/1/serie_45_Enrique_Ramos.pdf

Román, M y Cardemil C. (2014). Juego, interacción y material educativo en el nivel Preescolar. ¿Qué se hace y cómo se aprende? Iberoamericana de Evaluación Educativa, 7(1), 43-62. Disponible en https://repositorio.uahurtado.cl/ bitstream/handle/11242/9345/txt1078.pdf?sequence $=1$

Romero, M. (2004). El aprendizaje de la lecto-escritura. Lima. Perú. Fe y alegría.

Ruay, R. (2010). El rol del docente en el contexto actual. Desarrollo de Competencias (REDEG)

2(6), 1-9. Disponible en http://dta. utalca.cl/ojs/index.php/fcompeten $\% 20$ cias/article/viewFile/82/76

Sánchez, S y Yubero, G. (2015). Biblioteca en la Formación del Hábito Lector. España. UNE.

Swartz, S. (2010). Cada niño un lector: Estrategias innovadoras para enseñar a leer y escribir. Santiago. Chile. Universidad de Chile. 